\title{
Volatile Organic Compounds of Endophytic Burkholderia pyrrocinia Strain JK-SH007 Promote Disease Resistance in Poplar
}

\author{
Ake Liu, Pengfei Zhang, Bianxia Bai, Fenglin Bai, Tingting Jin, and Jiahong Ren ${ }^{\dagger}$ \\ Faculty of Biology Science and Technology, Changzhi University, Shanxi 046011, China
}

\begin{abstract}
Volatile organic compounds (VOCs) play important roles in the regulation of plant growth and pathogen resistance. However, little is known about the influence of VOCs released from endophytic strains (Burkholderia pyrrocinia strain JK-SH007) on controlling pathogens or inducing systemic resistance in poplar. In this study, we found that VOCs produced by strain JK-SH007 inhibit three poplar canker pathogens (Cytospora chrysosperma, Phomopsis macrospora, and Fusicoccum aesculi) and promote defense enzyme activity and malondialdehyde (MDA) and total phenol (TP) accumulation. Thirteen kinds of VOC components were identified using the solid-phase microextraction combined with gas chromatography-mass spectrometry method. Dimethyl disulfide (DMDS) accounted for the largest proportion of these VOCs. Treatments of poplar seedlings with different volumes of VOC standards (DMDS, benzothiazole, dimethylthiomethane, and phenylacetone) showed that DMDS had the greatest effects on various defense enzyme activities

DMDS significantly reduced the severity and development of the disease caused by three poplar canker pathogens. Comparative transcriptomics analysis of poplar seedlings treated with DMDS showed that there were 1,586 differentially expressed genes in the leaves and stems, and quantitative PCR showed that the gene expression trends were highly consistent with the transcriptome sequencing results. The most significant transcriptomic changes induced by VOCs were related to hormone signal transduction, transcriptional regulation of plant-pathogen interactions, and energy metabolism. Moreover, 137 transcription factors, including members of the ethylene response factor, NAC, WRKY, G2-like, and basic helix-loop-helix protein families, were identified to be involved in the VOC-induced process. This study elucidates the resistance induced by Burkholderia pyrrocinia strain JK-SH007 to poplar canker at the molecular level and can make possible a new method for the comprehensive prevention and control of poplar disease.
\end{abstract} and MDA and TP accumulation. We also found that the inhibitory effect of the VOCs on the three pathogens was gradually enhanced with increasing standard volume. Moreover, the treatment of samples with
Keywords: Burkholderia pyrrocinia, disease resistance, poplar canker, transcriptome sequencing, volatile organic compounds
Volatile organic compounds (VOCs) have long been considered a very effective chemical exchange medium (Wang et al. 2013). On the one hand, microorganisms produce and release VOCs for communication and defense, and VOCs inhibit the growth of many plant pathogens to varying degrees (Asari et al. 2016; Zhang et al. 2013, 2015; Zheng et al. 2013). For example, citronellol, benzothiazole, and 1octene-3-ol produced by Paenibacillus polymyxa BMP-11 inhibit the mycelial growth of eight common pathogens (Zhao et al. 2011). Fiddaman and Rossall (1993) demonstrated that VOCs produced by Bacillus subtilis NCIMB12376 could inhibit the growth of Rhizoctonia solani and Pythium ultimum. Studies have also revealed that many volatiles emitted by soil bacteria have antifungal activities and reduce hyphal extension as well as hyphal biomass (Effmert et al. 2012; Garbeva et al. 2014). On the other hand, VOCs promote plant growth and defense against various biotic and abiotic stresses (Bhattacharyya et al. 2015; Tahir et al. 2017). When plants perceive VOCs produced by microorganisms, the expression of some genes or related enzymes changes to accelerate the metabolism of

${ }^{\dagger}$ Corresponding author: J. Ren; renjiahong76@ hotmail.com

A. Liu and P. Zhang contributed equally to this work.

Funding: This work was financially supported by the National Natural Science Foundation of China (grant 31470645), the Fund for Shanxi "1331 Project" Key Subjects Construction (1331KSC), and the Fund for Shanxi Key Subjects Construction (FSKSC).

*The $\boldsymbol{e}$-Xtra logo stands for "electronic extra" and indicates that 10 supplementary figures and 3 supplementary tables are published online.

The author(s) declare no conflict of interest.

Accepted for publication 4 February 2020.

(C) 2020 The American Phytopathological Society nutrients and thus promote the growth of plants. For instance, VOCs produced by Bacillus subtilis GB03 and Bacillus amyloliquefaciens IN937a were shown to be novel determinants of both plant growth promotion and the elicitation of induced systemic resistance in Arabidopsis seedlings (Ryu et al. 2004). Because of the beneficial effects of plant rhizobacteria on plant growth and resistance to biotic/abiotic stresses resulting from strain-released VOCs, the biological control of plant diseases with bacterial antagonism is a much safer alternative than chemical control. Several studies have explored the control of plant diseases through antagonistic bacteria that are able to maintain plant pathogenic microbes below a given threshold.

Accordingly, the induction of plant resistance is often achieved through the responses of defense enzymes, and the activity of these enzymes is generally positively correlated with disease resistance. Studies have shown that the increase in defense enzymes such as polyphenol oxidase (PPO), peroxidase (POD), superoxide dismutase (SOD), $\beta$-1,3-glucanase (GLU), and phenylalanine ammonia lyase (PAL) in plants can improve plant disease resistance (D'Alessandro et al. 2014; Jain and Choudhary 2014; Lanna-Filho et al. 2013). These defense enzymes are usually used as important indicators of disease resistance. Some phenolic compounds can be oxidized to quinones by PPO to enhance plant resistance to pathogens; POD can promote lignin biosynthesis and reduce the concentration of intracellular reactive oxygen species; and SOD, as an antioxidant enzyme, can scavenge $\mathrm{O}^{2-}$, resist the toxicity of oxyradicals and other oxide radicals to the plasma membrane, and maintain the normal physiological metabolism of cells. GLU can decompose the glucan in the cell wall of fungi, thereby killing pathogens and preventing the invasion of plants by pathogens; PAL can synthesize many important antimicrobial substances in plants, including lignin, flavonoids, and phytoalexins (Chen et al. 2017; Cheniany and Ganjeali 2016; Jiang et al. 2013; Thiyagarajan et al. 2016; Vijayabharathi et al. 2018). In addition, malondialdehyde (MDA) content and total phenol (TP) content are important physiological indices for measuring oxidative damage under abiotic and biotic stress (Huang et al. 2016; Li et al. 2019a; Montero-Palmero et al. 2014). 
Transcriptome-wide analysis is a widely used approach to detect and understand the breadth of molecular mechanisms involved in physiological processes and thus increase the efficiency by which genes of interest are identified (Deng et al. 2019; Li et al. 2019b). RNA sequencing (RNA-Seq) provides an effective method for transcriptome analyses and is increasingly used for obtaining general profiles of RNA expression in both model and nonmodel species. Many studies concerning VOCs released by microorganisms have been reported (Lou et al. 2018; Tian et al. 2019; Yue et al. 2019). However, no such study has used RNA-Seq technology to investigate the expression profile of the genes involved in VOC-induced molecular mechanisms in poplar inoculated with VOCs of the endophytic Burkholderia pyrrocinia strain JK-SH007.

Burkholderia pyrrocinia strain JK-SH007 is a poplar stem isolate belonging to genomovar IX of the Burkholderia cepacia complex (Ren et al. 2011), which colonizes poplar stems and leaves endophytically, promoting plant growth and suppressing the pathogenic activities of poplar. However, little is known about the antifungal properties of this strain, including the inhibitory capacity of the VOCs produced by strain JK-SH007 on fungal pathogens. This study is the first report on the production and systemic resistance activities of VOCs derived from strain JK-SH007 against poplar disease. We demonstrated that VOCs not only control pathogens but also induce systemic resistance. After transcriptome sequencing, differentially expressed genes (DEGs) related to hormone signal transduction, transcriptional regulation of plant-pathogen interactions and energy metabolism were observed using RNA-Seq analysis. Our findings may provide new insights into the potential of bacterial VOCs as a biocontrol tool against poplar diseases.

\section{Materials and Methods}

Plant material and growth conditions. Poplar seedlings (Populus $\times$ euramericana ' $N L$ 895') were grown in plastic bottles $(65 \times$ $160 \mathrm{~mm}$ ) containing $100 \mathrm{ml}$ of half-strength Murashige and Skoog medium. Plants were grown at $25^{\circ} \mathrm{C}$ under long-day conditions ( $16 \mathrm{~h}$ of light during the day $/ 8 \mathrm{~h}$ of dark). These tissue culture seedlings were used for experiments after they were grown for 15 days.

Microbial strains. Burkholderia pyrrocinia JK-SH007 was isolated from the poplar stem in our previous work (Ren et al. 2011) and deposited in the China Center for Type Culture Collection under accession number M 209028. Strain JK-SH007 was cultured in nutrient agar (NA) medium at $30^{\circ} \mathrm{C}$ for $24 \mathrm{~h}$. Three fungal pathogens (Cytospora chrysosperma, Phomopsis macrospora, and Fusicoccum aesculi), which exhibited high virulence and had been isolated from naturally infected poplar stems (Wang and Wu 2008), were cultured on potato dextrose agar (PDA) plates at $28^{\circ} \mathrm{C}$ for approximately 4 days.

Antifungal activity of the VOCs of strain JK-SH007. Antifungal activity of the VOCs of strain JK-SH007 was examined using the two-sealed-baseplates method (Gao et al. 2017). One baseplate contained $15 \mathrm{ml}$ of NA, and another baseplate contained $15 \mathrm{ml}$ of PDA. Twenty microliters of a JK-SH007 suspension $\left(1.0 \times 10^{6} \mathrm{CFU} / \mathrm{ml}\right)$ was spread onto the surface of the NA plate, and 5-mm mycelial plugs of each pathogenic fungus were placed onto the centers of the PDA plates. Then, the two baseplates were sealed with polyethylene stretch-wrap and cultured at $28^{\circ} \mathrm{C}$ for 4 days. Control plates were prepared only with each pathogenic fungal inoculation. The percent of inhibition (PI\%) was calculated and expressed as

$$
\mathrm{PI} \%=(\mathrm{C}-\mathrm{T}) / \mathrm{C} \times 100
$$

where $\mathrm{C}$ is the growth of the pathogen and $\mathrm{T}$ is the growth of the pathogen in the presence of the bacteria. In addition, marginal mycelia exposed to bacterial VOCs for 7 days were selected and placed in water, and mycelial morphological changes were observed under an optical microscope (Zeiss). Each treatment was replicated three times, and every experiment was repeated three times.

Analysis of VOCs affecting poplar physiological indices. To estimate the effect of VOCs of Burkholderia pyrrocinia JK-SH007 on the activity of defense enzymes (PPO, POD, GLU, PAL and SOD), MDA content, and TP content in poplar tissue culture seedlings, poplar tissue culture seedlings were prepared with or without exposure to the VOCs of strain JK-SH007. Sterilized 5-ml beakers (containing $1 \mathrm{ml}$ of NA solid culture medium) were placed in plastic bottles with poplar seedlings. These $5-\mathrm{ml}$ beakers were placed as far away as possible from the seedlings. Then, $200 \mu \mathrm{l}$ of liquid culture of strain JK-SH007 was inoculated into the beaker. NA mediuminoculated samples served as a control. Disease resistance response indices were determined 3, 6, 9, and 12 days after treatment. Then, the defense enzyme activity, MDA content, and TP content of the poplar tissue culture seedlings were determined.

Determination of defense enzyme activity. Crude enzymes were extracted using the method proposed by Venisse et al. (2001) with some modifications. Tissue culture seedlings of NL895 were washed twice and suspended in sterilized water. A total of $500 \mathrm{mg}$ of leaf tissue was homogenized in 2 to $3 \mathrm{ml}$ of a solution containing $100 \mathrm{mM}$ of cold boric acid buffer ( $\mathrm{pH} 8.8$ ) and $2 \%$ (wt/vol) polyvinylpyrrolidone by grinding with washed quartz sand in a porcelain mortar. Then, the homogenate was centrifuged at $11,304 \mathrm{rpm}$ for $15 \mathrm{~min}$ at $4^{\circ} \mathrm{C}$, and the supernatant was collected and used to determine PPO, POD, GLU, PAL, and SOD activity and MDA content. Total protein content was calculated using the Bradford method (Bradford 1976). PPO activity was determined using the method proposed by Concellón et al. (2004). POD activity was assayed according to the method of $\mathrm{Yu}$ et al. (2004). PAL activity was estimated using previously described methods (Konappa et al. 2016). SOD activity was measured according to the method of Lu et al. (2010). GLU activity, MDA content, and TP content were determined by the methods of Sun et al. (2013).

A total of $5 \mathrm{~g}$ of frozen sample was homogenized with $20 \mathrm{ml}$ of $80 \%$ ethanol for $10 \mathrm{~min}$. The extract was then filtered and centrifuged at $8,000 \mathrm{rpm}$ for $15 \mathrm{~min}$. An aliquot $(0.5 \mathrm{ml})$ of extract was mixed with $1.5 \mathrm{ml}$ of Folin-Ciocalteu reagent and diluted 10 times. After $6 \mathrm{~min}, 2 \mathrm{ml}$ of $7 \% \mathrm{Na}_{2} \mathrm{CO}_{3}$ solution was added to the final mixture. Absorbance was measured after 90 min against a blank at $750 \mathrm{~nm}$. A standard curve of gallic acid was used to quantify the TP content, and the results were represented in milligrams per $100 \mathrm{~g}$ of fresh weight.

Sample preparation and VOC extraction conditions. The VOCs of strain JK-SH007 were characterized by headspace (HS) solid-phase microextraction (SPME) combined with gas chromatography (GC)-mass spectrometry (MS), as described previously (Dandurishvili et al. 2011), with minor modifications. Briefly, strain JK-SH007 was grown in 50-ml glass flasks containing $20 \mathrm{ml}$ of Luria-Bertani (LB) medium and incubated at $180 \mathrm{rpm}\left(30^{\circ} \mathrm{C}\right)$ for 2 days. Flasks were covered with four layers of tinfoil. After incubation, the flasks with the culture were equilibrated using a Hotplate/Stirrer (Henry Troemner LLC) at $40^{\circ} \mathrm{C}$ for $15 \mathrm{~min}$. The volatile compounds were extracted over the following $30 \mathrm{~min}$ at $40^{\circ} \mathrm{C}$ using a manual SPME fiber holder covered with a polydimethylsiloxane (PDMS)/divinylbenzene (65 $\mu \mathrm{m}$; Supelco Inc.) film. The fiber was conditioned at $260^{\circ} \mathrm{C}$ for $30 \mathrm{~min}$ by heating in the injection port of a GC system prior to use. After VOC extraction, the fiber was moved from the flask HS to the injection port of the GC-MS apparatus for analysis. Sterile LB served as the negative control, and all of the HS-SPME-GC-MS measurements were conducted in triplicate for each PDMS sample.

The VOCs were analyzed by a GC/MS system (QP2010 Plus; Shimadzu $)$ equipped with a DM-5 capillary column $(30 \mathrm{~m} \times 0.32 \mathrm{~mm} \times$ $0.25 \mu \mathrm{m}$; Dikma Technologies). The HS-SPME extract was desorbed from the fiber at $260^{\circ} \mathrm{C}$ for $3 \mathrm{~min}$ in the $\mathrm{GC}$ injection port. The injection port was operated in split mode, and the split ratio was $30 \%$. The carrier gas was $99.999 \%$ pure helium with a constant flow rate of $1.4 \mathrm{ml} / \mathrm{min}$. The oven temperature program was set at $40^{\circ} \mathrm{C}$ for $5 \mathrm{~min}$, raised to $95^{\circ} \mathrm{C}$ at a rate of $10^{\circ} \mathrm{C} / \mathrm{min}$, raised to $230^{\circ} \mathrm{C}$ at a rate of $3^{\circ} \mathrm{C} / \mathrm{min}$, and then held at $230^{\circ} \mathrm{C}$ for $5 \mathrm{~min}$. Finally, the temperature was raised to $260^{\circ} \mathrm{C}$ at a rate of $10^{\circ} \mathrm{C} / \mathrm{min}$ and maintained at $260^{\circ} \mathrm{C}$ for the next sample. The mass spectra were obtained by electronic impact at $70 \mathrm{eV}$, and the electron ionization source temperature was maintained at $250^{\circ} \mathrm{C}$. VOC identification was conducted using the NIST08 Library database. The relative content of each peak was calculated by normalization of the peak area. 
Antifungal activity of four main VOC compounds on pathogens. Antifungal activity of the four main VOC compounds (dimethyl disulfide [DMDS], dimethylthiomethane, propiophenone, and benzothiazole) of strain JK-SH007 was assessed using plastic Petri dishes ( $80 \mathrm{~mm}$ in diameter) with a central partition. These Petri dishes were used because the media share only the HS above the culture medium and thus avoid contact. Pathogens were inoculated on one side of the partition, and VOCs were inoculated on the other side of the partition. Prior to exposure to bacterial VOCs, pathogens were cultured on PDA medium. First, a 5-mm mycelial plug of each pathogenic fungus was inoculated gently in the center of a PDA medium compartment. Then, a glass baseplate (30 $\mathrm{mm}$ in diameter) was placed in the middle of another compartment, and different volumes of different VOCs $(20,40,60$, and $80 \mu \mathrm{l})$ were added to small glass Petri dish covers to test pathogen growth. Moreover, Petri dishes were sealed with Parafilm to minimize air contact and incubated at $28^{\circ} \mathrm{C}$. Control plates were prepared with each pathogenic fungal inoculation only. Then, the PI\% was calculated, and the mycelial morphological changes were observed under an optical microscope. The experiment was repeated three times with three replicates each time.

Effects of four main VOC compounds on the disease resistance response indices of poplar. To estimate the effect of the four main VOCs (DMDS, dimethylthiomethane, propiophenone, and benzothiazole) of strain JK-SH007 on the poplar seedlings' disease resistance response indices (PPO, POD, GLU, PAL, SOD, MDA, and TP), poplar tissue culture seedlings were prepared with or without exposure to the standard products. A 5-ml beaker was placed into each poplar seedling bottle. Then, different volumes of standard products $(2.5,5$, and $7.5 \mu \mathrm{l})$ were placed into the beakers. At the same time, uninoculated samples served as controls. Analyses of the disease resistance response indices were performed 3, 6, 9, and 12 days after treatment.

Biocontrol activity of DMDS. The tissue culture seedlings of poplar were cultivated as described by Ren et al. (2011) and used as tests for the biocontrol activity of stem canker by DMDS. Three pathogens were chosen for this experiment. Inoculation sites were selected on the surface of the poplar trunk between 80 and $100 \mathrm{~mm}$ from the surface of the medium. Seedlings were then wounded to the xylem with sterile acupuncture needles $(0.35 \times 100 \mathrm{~mm})$ at the inoculation sites (five scalds per seedling). The conidium suspension of three pathogens (conidia $>10^{5} \mathrm{ml}^{-1}$ ) was spread on the surface of the scalds with a small brush $(50 \mu \mathrm{l}$ per plant). Noninoculated seedlings were used as negative controls. Then, $7.5 \mu \mathrm{l}$ of DMDS was added to each 5-ml beaker in the bottles with inoculated poplar seedlings. At the same time, seedlings inoculated by pathogens without exposure to $7.5 \mu \mathrm{l}$ of DMDS were used as positive controls. The disease severity was recorded (Ren et al. 2011) every 2 days until 30 days after inoculation. Finally, the disease index (Di) and control effects (Ce) of pathogens were computed according to the disease severity.

RNA extraction and library construction. Six aseptic poplar seedlings with good growth and uniformity were selected after 1 week. DMDS $(7.5 \mu \mathrm{l})$ was inserted into a 5 -ml beaker. At the same time, a beaker containing no DMDS was used as a blank control. Each treatment was repeated three times. Samples were incubated in an intelligent artificial climate incubator at $25^{\circ} \mathrm{C}$ with a 16 -h/8-h light/dark cycle and $72 \%$ humidity for 9 days. The stem and leaf tissues were collected and stored at $-80^{\circ} \mathrm{C}$ in liquid nitrogen until RNA extraction. RNA was isolated using the RNeasy Plant Mini Kit (74904; QIAGEN) following the manufacturer's instructions. The RNA quantities and qualities of each sample were analyzed with NanoDrop (Thermo Fisher Scientific) and Qubit 2.0 (Life Technologies) instruments. Approximately $5 \mu \mathrm{g}$ of RNA per sample was used as input material. After two purifications, only mRNA was retained. The NEBNext Ultra RNA Library Prep Kit for Illumina was used for RNA-Seq library preparation, with 15 PCR cycles for library amplification. Libraries were sequenced on an Illumina HiSeq 2500. Quality control of raw reads was performed with FastQC software (version 0.11.5). After clipping Illumina adapter sequences and trimming low-quality bases through in-house Perl scripts, clean reads were kept for further analysis.

Read alignment and transcript assembly. First, the clean reads of each sample were mapped against a reference genome deposited in the NCBI database (Populus trichocarpa, assembly Poptr2_0) using TopHat 2.0.9 (Kim et al. 2013) with default parameter settings. Then, the aligned reads were assembled into genes using Cufflinks 2.1.1 (Trapnell et al. 2010), and the relative abundance of each transcript was determined by calculating the fragments per kilobase of exon per million fragments mapped (FPKM) of mRNA (coding gene) in each sample. Second, Cuffmerge 2.1.1 was used to merge samples based on their treatment patterns to obtain gene expression levels. Then, the expression levels of genes in different groups were obtained. Finally, the differential transcript expression between pairs of samples was analyzed using Empirical Analysis of Digital Gene Expression in R (edgeR; version 3.22.5) (Robinson et al. 2010). The calculated $P$ values were subjected to the Benjamini-Hochberg method to control for the false discovery rate (FDR) (Benjamini and Hochberg 1995). Genes with an FDR $<0.05$ and an estimated absolute $\log _{2}$ (fold change) $>1$ were regarded as DEGs.

Functional enrichment analysis. For the Gene Ontology (GO) and Kyoto Encyclopedia of Genes and Genomes (KEGG) pathway enrichment analyses, we first obtained the GO terms and KEGG pathways of DEGs and all of the genes of poplar from the Gene Ontology Consortium (http://geneontology.org) and KEGG websites, respectively (Gene Ontology Consortium 2015; Kanehisa et al. 2016). To test the significance of the DEG annotations, we conducted a hypergeometric test to find the GO terms or KEGG pathways that were significantly enriched in DEGs compared with genome-wide genes. The significance threshold was set at $P$ values $<0.05$.

Real-time quantitative PCR. To validate the reliability of the RNA-Seq results, we randomly selected 20 genes for real-time quantitative PCR analysis with three biological replicates. The analysis was conducted using the Mastercycler ep RealPlex4S (Eppendorf) with Applied Biosystems Power SYBR Green PCR Master Mix (4367659; Life Technologies). Real-time PCR was carried out in a final volume of $20 \mu \mathrm{l}$, which contained $1 \mu \mathrm{l}$ of cDNA, $10 \mu \mathrm{l}$ of $2 \times$ SYBR Green, $1.6 \mu l$ of primer mix, and $7.4 \mu \mathrm{l}$ of DNase-free/RNase-free $\mathrm{H}_{2} \mathrm{O}$. The cycling program was set as follows: initial denaturation at $95^{\circ} \mathrm{C}$ for $10 \mathrm{~min}, 40 \mathrm{cy}-$ cles of denaturation at $95^{\circ} \mathrm{C}$ for $15 \mathrm{~s}$, and annealing and extension at $60^{\circ} \mathrm{C}$ for $30 \mathrm{~s}$. A melting curve was obtained at $95^{\circ} \mathrm{C}$ for $5 \mathrm{~s}$ and $60^{\circ} \mathrm{C}$ for $1 \mathrm{~min}$ followed by continuous heating. The ubiquitin gene was used as a reference gene. The results were analyzed with integrated Mastercycler ep RealPlex4S service software. The primers are shown in Supplementary Table S1. The relative expression of each target gene was calculated by the $2^{-\triangle \triangle \mathrm{Ct}}$ method.

\section{Results}

VOCs produced by Burkholderia pyrrocinia JK-SH007 have inhibitory effects on three poplar canker pathogens. Burkholderia pyrrocinia strain JK-SH007 produces VOCs, which have a certain inhibitory effect on poplar canker pathogens. To study the effects of these VOCs, we incubated three poplar canker pathogens with strain JK-SH007 cultures for 4 days at $28^{\circ} \mathrm{C}$. As shown in Table 1, the inhibition rates of $C$. chrysosperma, $P$. macrospora, and $F$. aesculi were $45.51,21.69$, and $43.82 \%$, respectively (Table 1; Supplementary Fig. S1). The results indicated that VOCs produced by strain JK-SH007 had obvious antagonistic effects on the three pathogens, especially on $C$. chrysosperma and $F$. aesculi (Table 1; Supplementary Fig. S1). The marginal hyphae of these three pathogens were selected for microscopic observation. The VOCs of JKSH007 caused an abnormal change in the morphology of the three types of fungal hyphae to different degrees (Supplementary Fig. $\mathrm{S} 2$ ). After incubation with strain JK-SH007 cultures, C. chrysosperma hyphae became thicker, shriveled, twisted, and less flexible (Supplementary Fig. S2A). In addition, P. macrospora hyphae became thicker, with an inner protoplasm that aggregated into lumps (Supplementary Fig. S2B), and F. aesculi hyphae became thicker and highly enlarged (Supplementary Fig. S2C).

The main physiological indices in poplar change postinoculation with VOCs. To determine the effects of VOCs on the physiological and biochemical characteristics of poplar, we measured changes in defense enzyme activity, MDA content, and TP content in poplar tissue culture seedlings treated with VOCs produced by strain JK-SH007. 
As shown in Figure 1, we measured disease resistance response indices at 3, 6, 9, and 12 days after treatment. Previous studies indicated that PPO, POD, GLU, PAL, and SOD are closely related to plant defense functions. Compared with the control, activity of PPO and SOD in the treatment increased significantly and peaked on day 9 (Fig. 1A and B). Consistent with PPO enzyme activity, POD activity peaked in both the control and treatment groups on day 9. Moreover, there was a significant difference between the control and treatment groups (Fig. 1C). PAL activity in the treatment group was significantly higher than that in the control group, peaking on day 9 for the treatment group and on day 12 for the control group (Fig. 1D). GLU activity in the treatment group was significantly higher than that in the control group on day 3 . On days 6 and 9, activity in both groups decreased significantly. On day 12 , GLU activity began to rise again but there were significant differences among the four time points (Fig. 1E).

Decreases in MDA content could enhance the antilipid peroxidation of cells and the ability of cells to resist pathogen infection and damage. On day 3, MDA content in the treatment group was significantly higher than that in the control. Moreover, MDA content peaked on day 6 and then decreased gradually, but MDA content in the treatment group was significantly lower than that in the control (Fig. 1F). Phenolic substances, types of secondary metabolites secreted by plants, are closely related to plant disease resistance and can inactivate the activity of some hydrolytic enzymes secreted by pathogens and promote lignification of the cell wall. As shown in Figure 1G, TP content increased and peaked on day 9. On day 12, TP content decreased but total content in the treatment group was still higher than that in the control.

Table 1. Antagonistic function of volatile organic compounds of strain JKSH007 to three poplar canker pathogens ${ }^{\mathrm{z}}$

\begin{tabular}{lccl}
\hline Treatment & $\begin{array}{c}\text { Cytospora } \\
\text { chrysosperma }(\mathbf{m m})\end{array}$ & $\begin{array}{c}\text { Phomopsis } \\
\text { macrospora }(\mathbf{m m})\end{array}$ & $\begin{array}{c}\text { Fusicoccum } \\
\text { aesculi }(\mathbf{m m})\end{array}$ \\
\hline Strain JK- & $50.76 \pm 0.93 \mathrm{~b}$ & $68.06 \pm 1.00 \mathrm{~b}$ & $50.47 \pm 1.65 \mathrm{~b}$ \\
SH007 & & & \\
Control & $88.97 \pm 0.70 \mathrm{a}$ & $85.56 \pm 0.88 \mathrm{a}$ & $85.93 \pm 0.87 \mathrm{a}$ \\
Inhibition & 45.51 & 21.69 & 43.82 \\
rate $(\%)$ & & & \\
\hline
\end{tabular}

${ }^{\mathrm{z}}$ Values are presented as means \pm SD unless otherwise indicated. Values with different lowercase letters in a column are significantly different $(P<0.05)$.
DMDS identified as the major component of the VOCs. Because of the effects of VOCs on defense enzymes, MDA content, and TP content in poplar as well as their significant inhibitory effect, it was necessary to detect the composition of VOCs. The SPME-GC-MS method was used to determine VOCs in strain JKSH007 fermentation broth. The results showed that there were approximately 13 types of VOCs in the strain JK-SH007 fermentation broth: namely, DMDS, methyl iminobenzoate, dimethylthiomethane, phenylacetone, dimethyl trisulfide, 3-propoxy-1-propene, aromatic phenyl acetone, 1-methyl-2-methylthiomethyl disulfide, 4-methyl2,3-pentanediol, 2-methylvaleraldehyde, benzothiazole, 6-methyl3-heptanone, and acetophenone (Table 2). Among these VOCs, DMDS accounted for the largest proportion (approximately $84.8 \%$ ) and may be the most important component of JK-SH007-induced poplar disease resistance.

Effects of four main VOC components on three pathogens of poplar canker disease. To determine the effect of VOCs (DMDS, dimethylthiomethane, propiophenone, and benzothiazole) on the pathogenic fungi of poplar canker, three pathogens $(C$. chrysosperma, $P$. macrospora, and $F$. aesculi) were treated with different volumes of VOCs, and the antimicrobial effect of each VOC component was determined by microscopic observation of mycelial

Table 2. Compound classes of the volatile organic compounds produced by strain JK-SH007

\begin{tabular}{lcc}
\hline Name & Retention time (min) & Area \% (A) \\
\hline Dimethyl disulfide & 9.871 & 84.80 \\
Dimethylthiomethane & 14.415 & 0.43 \\
Methyl iminobenzoate & 14.968 & 1.43 \\
Dimethyl trisulfide & 17.163 & 0.24 \\
6-Methyl-3-heptanone & 17.798 & 0.08 \\
Acetophenone & 20.360 & 0.07 \\
3-Propoxy-1-propene & 21.646 & 0.24 \\
1-Methyl-2-methylthiomethyl & 22.817 & 0.18 \\
disulfide & & \\
Phenyl acetone & 24.294 & 0.29 \\
Benzothiazole & 26.750 & 0.11 \\
2-Methylvaleraldehyde & 30.104 & 0.14 \\
4-Methyl-2,3-pentanediol & 33.149 & 0.18 \\
Aromatic phenyl acetone & 33.933 & 0.19 \\
\hline
\end{tabular}
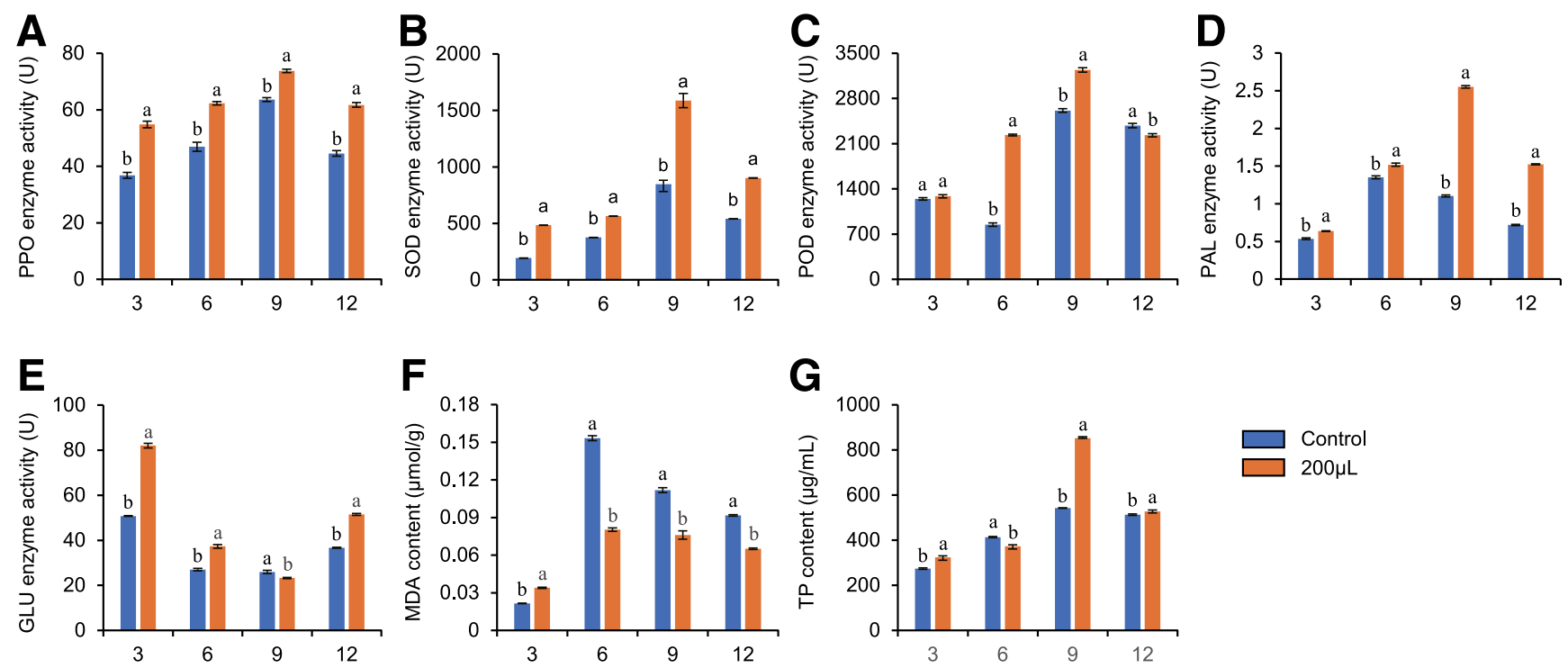

Fig. 1. Effect of volatile organic compounds (VOCs) released from strain JK-SH007 on different physiological indices of poplar. The graphs show the differences in $\mathbf{A}$, polyphenol oxidase (PPO), B, superoxide dismutase (SOD), C, peroxidase (POD), D, phenylalanine ammonia lyase (PAL), and E, $\beta$-1,3-glucanase (GLU) activity; and F, malondialdehyde (MDA) content and G, total phenol (TP) content among the control and treatments of $200 \mu \mathrm{l}$ of VOCs produced by strain JK-SH007 after 3, 6, 9, and 12 days of treatment, respectively. Values with different letters in a column are significantly different $(P<0.05)$. 
morphology. First, we determined the antimicrobial activity of the four components on different pathogenic fungi in a dish culture. The results showed that the inhibition rates of the different components on the three pathogens varied greatly at lower dosages, but the difference gradually decreased with increasing dosage (Fig. 2A to C). Among the VOCs, DMDS and dimethyl trisulfide had the best inhibitory effect. For instance, 20 to $80 \mu \mathrm{l}$ of DMDS/dish inhibited the mycelial growth of the three pathogens by the following percentages: $84.59,87.30,91.69$, and $94.26 \%$ for $C$. chrysosperma; 41.65 , 59.92, 84.66, and $91.08 \%$ for $F$. aesculi; and 85.91, 91.34, 93.87, and $96.05 \%$ for P. macrospora (Fig. 2D to F). As the DMDS content increased, the inhibitory effect of DMDS on the three poplar canker pathogens also increased (Fig. 2).

C. chrysosperma mycelia in the control grew vigorously, smoothly, and slenderly and had a random distribution. However, the mycelia became thickened, curved, severely segmented, densely distributed, and enlarged after treatment with $60 \mu 1$ of DMDS (Supplementary Fig. S3A). F. aesculi mycelia in the control grew vigorously and were straight, whereas the lateral buds of the mycelia inoculated with $60 \mu \mathrm{l}$ of DMDS increased and thickened slightly and the inner protoplasm aggregated greatly (Supplementary Fig. S3B). In the control, the P. macrospora mycelia grew vigorously, smoothly, and slenderly, and the protoplasm aggregated into obvious lumps. In the treatment group, the mycelia became shorter and slightly deformed and the inner protoplasm aggregated into lumps (Supplementary Fig. S3C). For the other three VOC components, the mycelia of the three pathogens underwent significant changes, as shown in Supplementary Figures S4, S5, and S6.

Effects of four main VOC components on the physiological indices of poplar. Previous studies have shown that the role of VOCs released from microorganisms in the process of growth promotion is generally played by a single component. To determine the effects of VOCs on poplar physiological indices, we used standard VOC components with different volumes and measured defense enzyme activity, MDA content, and TP content 3, 6, 9, and 12 days after treatment. First, we treated poplar culture seedlings with different volumes of the DMDS standard and found that PPO activity in the control was the highest on day 6; in the treatment group, PPO activity was the highest and most significantly different from the control level on day 9. The larger the volume of DMDS added, the higher the PPO enzyme activity (Fig. 3A). SOD activity peaked on day 9 when 2.5 and $5 \mu \mathrm{l}$ of DMDS was added. In particular, when $7.5 \mu$ l of DMDS was applied, there was no significant difference between the control and the treatment during the total process (Fig. 3B). The POD activity of poplar seedlings peaked and was significantly different from the control level on day 9 under $7.5 \mu \mathrm{l}$ of DMDS exposure (Fig. 3C). PAL activity peaked on day 9 and then decreased significantly on day 12 (Fig. 3D). GLU activity of the 7.5- $\mu$ l DMDS treatment was significantly higher than that of the control during the total process and peaked on day 9 (Fig. 3E).

MDA content in the treatment and control increased in the first 6 days and decreased in the treatment on day 9, especially in the 7.5- $\mu$ l treatment. Then, the MDA content in the treatment and control increased on day 12 (Fig. 3F). On day 3, $7.5 \mu \mathrm{l}$ of DMDS significantly decreased the TP content. Moreover, there was no significant difference between the treatment and control for other DMDS volumes. TP content decreased significantly on days 6 and 9 and then increased on day 12 (Fig. 3G). From days 6 to 12, the TP content of the 7.5- $\mu$ l DMDS treatment was significantly higher than that of the control and other treatments.

Similarly, poplar culture seedlings were treated with different volumes of dimethylthiomethane, propiophenone, and benzothiazole, and defense enzyme activity, MDA content, and TP content were measured 3, 6, 9, and 12 days after treatment (Supplementary Figs. S7, S8, and S9). In total, the results showed that DMDS, among the four VOC components, had the greatest effect on defense enzyme activity, MDA content, and TP content, and the greatest effect occurred 9 days after treatment with $7.5 \mu l$ of DMDS. The other three types of VOCs affected these indices, but their effects were not obvious or had no obvious regularity.

Control of poplar stem canker by DMDS. DMDS had good Ce on poplar canker (Table 3). The results showed that DMDS had $77.43,83.89$, and $82.31 \%$ Ce against poplar canker caused by $C$. chrysosperma, $P$. macrospora, and $F$. aesculi, respectively. The infection rate and the Di of plants inoculated with DMDS were significantly lower than those of plants uninoculated with DMDS. The Ce values of DMDS were equivalent to the inhibition of mycelial growth of the three pathogens in vitro. Therefore, inoculation with DMDS could significantly reduce the severity and development of poplar canker disease, and DMDS is a potential biocontrol agent.

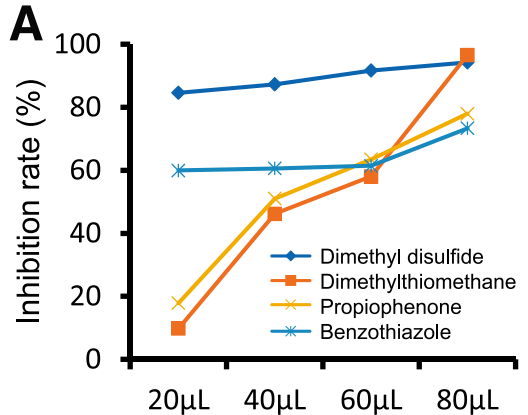

D

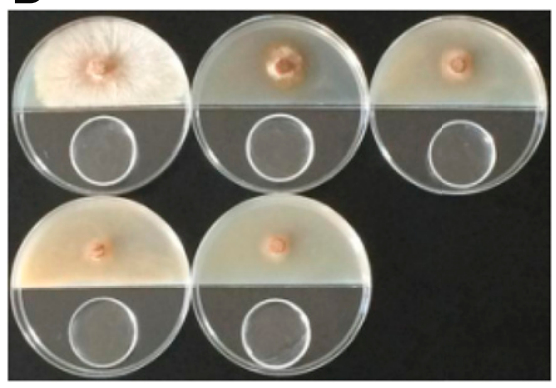

B

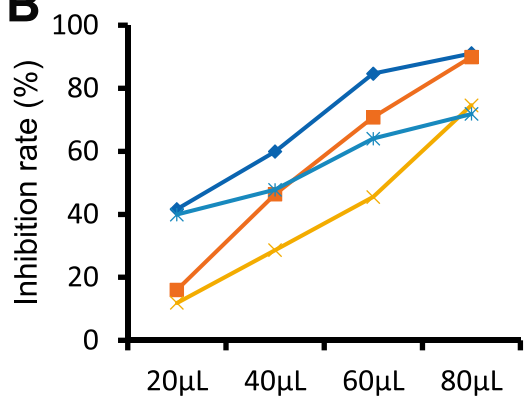

E

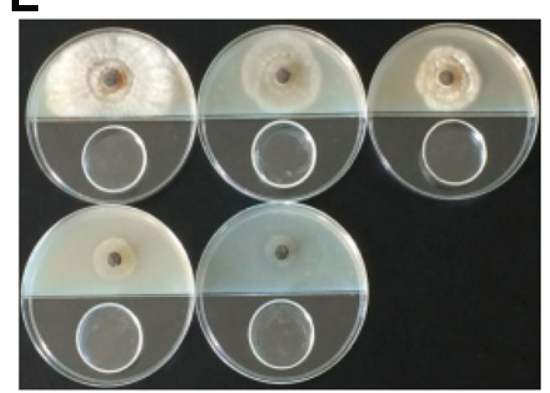

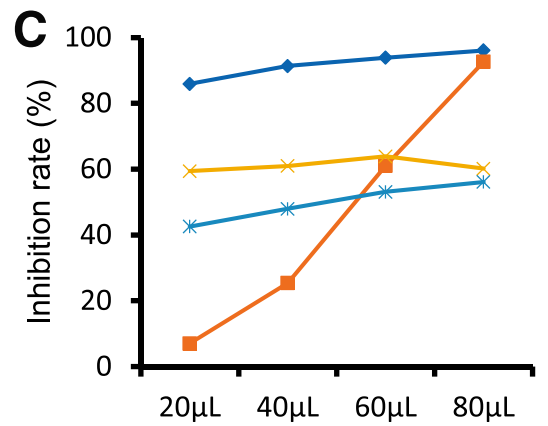

$\mathbf{F}$

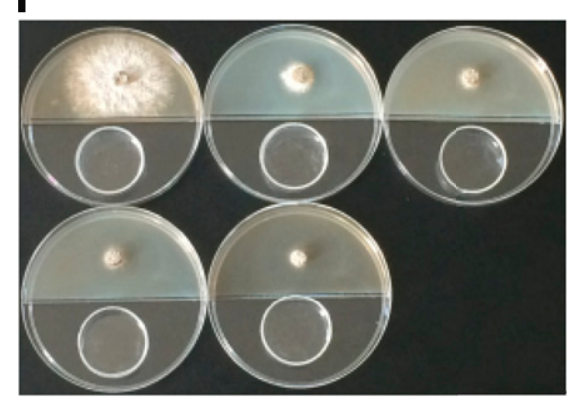

Fig. 2. The inhibitory rate of the main volatile organic compounds (VOCs) with different volumes on three poplar canker pathogens. A, B, and C, Inhibition rates of the four main VOCs on three poplar canker pathogens (Cytospora chrysosperma, Phomopsis macrospora, and Fusicoccum aesculi) using a volume gradient (20, 40, 60, and 80 $\mu$ I). D, E, and F, Inhibitory rates of dimethyl disulfide (DMDS) for the three poplar canker pathogens with CK and 20, 40, 60, and $80 \mu$ l from the upper left to lower right, respectively. 
Transcriptome profiles and DEGs of poplar stem and leaf samples induced by DMDS. To characterize the mechanism underlying poplar resistance induced by strain JK-SH007 and identify genes related to disease resistance, we added $7.5 \mu 1$ of DMDS to poplar tissue culture seedlings for 9 days and then the poplar stem and leaf tissues from the treatment and control were sequenced using RNA-Seq. First, we measured transcript levels in terms of FPKM based on RNA-Seq data for each sample. As shown in Figure 4A, the Pearson's correlation coefficients were $>90 \%$ among biological replicates in each sample. Those genes were regarded as DEGs if they showed at least a 2 -fold change in transcript abundance (FDR < $0.05)$. In total, 1,586 DEGs were identified in leaves or stems after treatment with DMDS in poplar tissue culture seedlings (Fig. 4B). In the leaves, there were 685 upregulated genes and 363 downregulated genes. In the stems, there were 271 upregulated genes and 445 downregulated genes. Comparing the DEGs of leaves and stems, we found that the shared DEGs only accounted for a small portion of the DEGs, regardless of whether the genes were upregulated or downregulated (Fig. 4C). These quantitative real-time PCR (qRT-PCR) analyses of genes such as PtTLP1, PtERF2, PtCIIIPRX, PtPAL, $P t E R F 106$, and $P t \beta-1,3-G s$ further confirmed the validity of the transcriptome datasets (Fig. 4D and E; Supplementary Fig. S10).

To further understand the putative active functions of DEGs, we conducted GO enrichment and KEGG pathway analyses based on a hypergeometric test of all DEGs. As shown in Supplementary Table S2, we itemized the 106 and 150 significantly enriched GO terms in leaves and stems, respectively, for DEGs between the treatment and control. Although there were fewer shared DEGs between leaves and stems, those genes were significantly involved in similar biological processes (Fig. 4F). The significantly enriched GO terms shared by both leaves and stems included the following: immune system process, multiorganism process, signaling, metabolic process, biological regulation, response to stimulus, reproduction, growth, cellular process, localization, reproductive process, cellular component organization or biogenesis, single-organism process, developmental process, and multicellular organismal process (Supplementary Table S2). This may indicate that the majority of genes involved in these biological processes underwent significant changes in both stems and leaves under DMDS exposure.

In total, 9 and 10 KEGG pathways were significantly enriched for the leaf and stem DEGs, respectively (Supplementary Table S3). Among them, two of these pathways, named plant hormone signal transduction and starch and sucrose metabolism, were shared by the two gene sets (Fig. 4G and H). In leaves, these DEGs can be allocated into 84 metabolic pathways. For instance, plant-pathogen interaction and cutin, suberine, and wax biosynthesis were significantly enriched. The stem DEGs belonged to 71 metabolic pathways, including fatty acid metabolism, sugar metabolism, and amino acid metabolism. Secondary metabolic pathways, such as anthocyanin biosynthesis and terpenoid biosynthesis, accounted for the majority of DEGs. This indicates that the metabolic pathways related to disease resistance and growth in leaves changed significantly after induction by DMDS.

Regulation of key DEGs in plant-pathogen-related immunity and hormone signal transduction. Because of the antifungal activity of poplar seedlings inoculated with VOCs, we further characterized the DEGs involved in plant-pathogen-related immunity using the KEGG database. Plant pattern recognition receptors trigger the recognition of pathogen-associated molecular patterns (PAMPs; elicitors), and the conserved domain in EF-Tu leads to PAMP-triggered immunity (Schwessinger and Zipfel 2008). Furthermore, the recognition of pathogen virulence proteins (effectors) or plant disease resistance genes initiates effector-triggered immunity (Dodds and Rathjen 2010). Twenty-eight DEGs were found to be involved in plant-pathogen interactions in either leaves or stems, among which six common DEGs were identified in both leaves and stems (Fig. 5A and B). The leaves presented more DEGs involved in plant-pathogen interactions than the stems, and this pathway was significantly enriched in leaves but not stems. This may indicate that the leaves play more important roles in pathogen resistance than the stems. The majority of the predicted functions of these DEGs were disease resistance proteins, transcription factors (TFs), protein kinases, or calcium binding proteins. As shown in Figure 5A, many genes, such as CDPK, CALM, and WRKY22, were upregulated in seedlings inoculated with DMDS.

Plant hormones are reported to be involved in symptom formation during phytoplasma infection (Fan et al. 2014). In our study, 26 DEGs related to hormone signal transduction, such as auxin, cytokinin, abscisic acid (ABA), ethylene, brassinosteroid, and salicylic acid (SA) signal transduction, were identified from leaves or stems under DMDS treatment (Fig. 5C and D). Of those, 5 DEGs were shared in the leaves and stems, whereas 14 and 7 DEGs were only present in the leaves and stems, respectively, indicating both common and tissue-specific regulation under VOC treatment. Fifteen genes in the auxin signaling pathway were differentially expressed, including one AUX1, eight Aux/IAA, three GRETCHEN HAGEN 3 (GH3), and three small auxin upregulated RNA (SAUR) genes. It has been shown that auxins have antiphytoplasma activity (Ćurković Perica 2008). ABA is a key hormone that plays an important role in plant growth and development and variable stress adaptation (Cutler et al. 2010). Three genes encoding the ABA receptor PYR/PYL
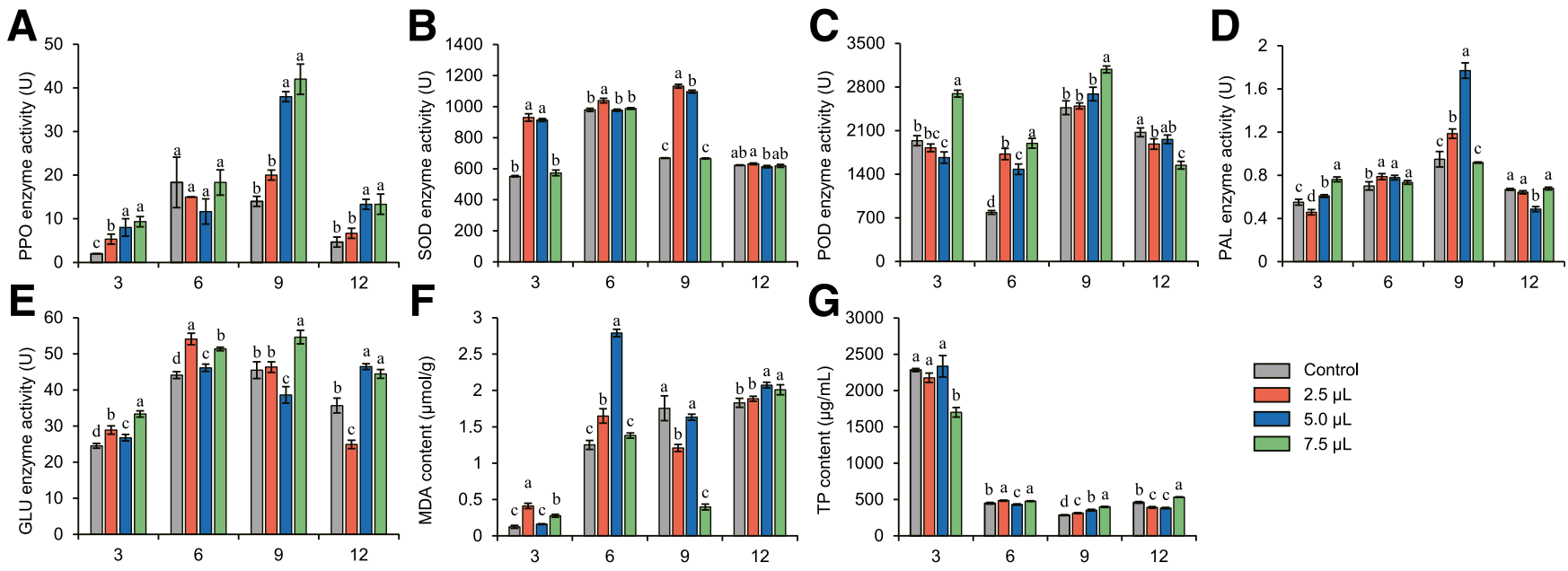

Fig. 3. Effect of dimethyl disulfide (DMDS) with volume gradients on different physiological indices of poplar after 3,6, 9, and 12 days of treatment. The graphs show the differences in A, polyphenol oxidase (PPO), B, superoxide dismutase (SOD), C, peroxidase (POD), D, phenylalanine ammonia lyase (PAL), and E, $\beta-1,3-g$ lucanase (GLU) activity; and $\mathbf{F}$, malondialdehyde (MDA) content and G, total phenol (TP) content among the control and treatments with 2.5, 5, and $7.5 \mu$ l of DMDS after 3, 6, 9, and 12 days, respectively. Values with different letters in a column are significantly different $(P<0.05)$. 
family related to ABA signaling were upregulated in both the stems and leaves. Six genes related to ethylene signaling were downregulated during the VOC-induced process. In the SA signaling pathway, one regulatory protein, NPR1, was upregulated after incubation with DMDS. A previous study indicated that plant hormones, such as ethylene, jasmonate, and SA, play a pivotal role in promoting host resistance (Dalio et al. 2017).

Differential expression of TFs involved in the DMDS response. TFs are involved in plant development and stress tolerance and can activate a cascade of downstream gene expression (Meshi and Iwabuchi 1995). Our transcriptomic data characterized some TFs governing the massive and highly coordinated transcriptional changes under DMDS treatment (Fig. 6). In total, 137 putative TFs, which could be categorized into 24 families, were identified from the DEG pools (Fig. 6A and B). As shown in Figure 6C, the differentially expressed TFs in leaves belonged to 21 families, such as the basic region/leucine zipper motif (bZIP) family, ethylene-responsive factor (ERF) family, WRKY family, basic helix-loop-helix (bHLH) family, and $\mathrm{C} 2 \mathrm{H} 2$ type zinc finger family. Transcripts encoding TFs such as ERF, NAC, WRKY, G2like, and bHLH were significantly upregulated in both leaves and stems after inoculation with DMDS (Fig. 6C and D). In particular, all WRKY family members were found to be upregulated in both stems and leaves in this study. These TFs are reported to be linked to stress resistance in plants (Amorim et al. 2017). The highly upregulated expression of TFs could play an important role in the promotion of plant growth and disease resistance in poplar seedlings by VOCs.

\section{Discussion}

Poplar canker disease is a serious poplar branch disease that is difficult to control because there are many types of poplar canker pathogens and various symptoms (Ren et al. 2013). Many microorganisms produce VOCs, which have a certain inhibitory effect on pathogens and great biocontrol potential (Liu et al. 2014; Ren et al.

Table 3. Effectiveness of dimethyl disulfide (DMDS) in controlling poplar canker caused by three pathogens ${ }^{\mathrm{z}}$

\begin{tabular}{lcccccccc}
\hline & \multicolumn{2}{c}{$\begin{array}{c}\text { Cytospora } \\
\text { chrysosperma }\end{array}$} & & \multicolumn{2}{c}{$\begin{array}{c}\text { Phomopsis } \\
\text { macrospora }\end{array}$} & & \multicolumn{2}{c}{$\begin{array}{c}\text { Fusicoccum } \\
\text { mesculi }\end{array}$} \\
\cline { 2 - 3 } \cline { 8 - 9 } Treatment & $\mathbf{D i}^{\mathbf{y}}$ & Ce (\%) & & Di & Ce (\%) & & Di & Ce (\%) \\
\hline DMDS & 20 & 77.43 & & 14.45 & 83.89 & & 15.55 & 82.31 \\
Control & 88.33 & - & & 90 & - & & 87.78 & - \\
\hline
\end{tabular}

${ }^{\mathrm{z}} \mathrm{Di}$, disease index; $\mathrm{Ce}$, control effects. $\mathrm{Di}$ and $\mathrm{Ce}$ are computed by the following equation:

$\mathrm{Di}=[\Sigma($ Scale $\times$ Number of plants infected $) /($ Highest scale $\times$ Total number of plants) $] \times 100$

$\mathrm{Ce}(\%)=[(\mathrm{Di}$ of the control $\times \mathrm{Di}$ of the treatment with DMDS $) /(\mathrm{Di}$ of the control) $] \times 100$
A

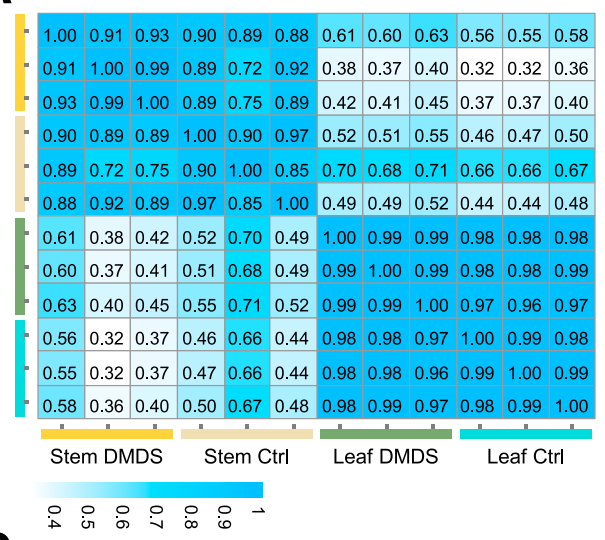

B

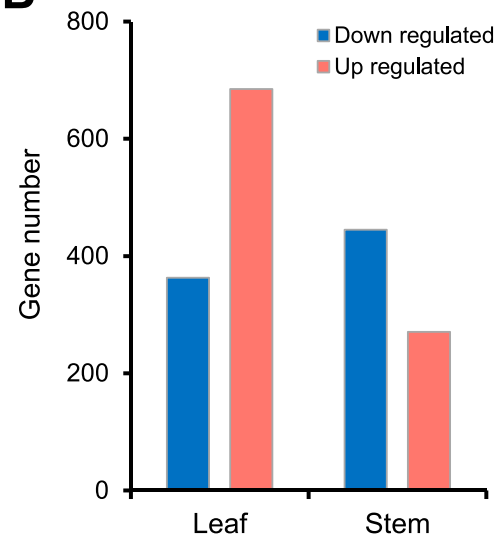

C

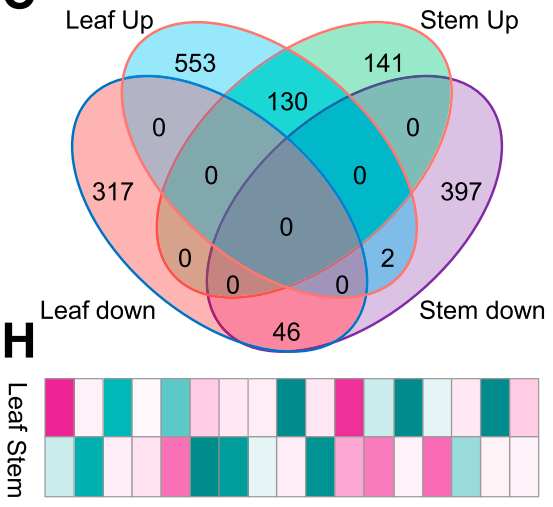

믐믕
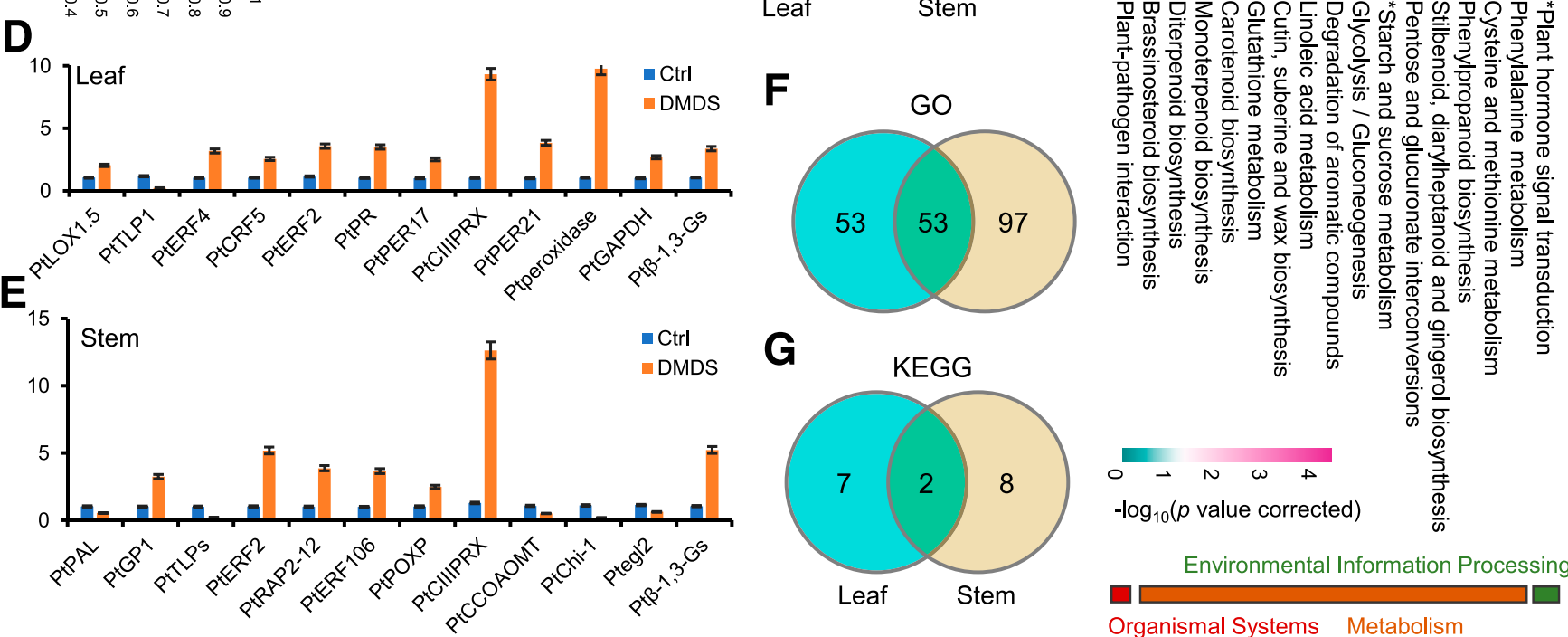

Environmental Information Processing

Organismal Systems Metabolism

Fig. 4. Comparisons of expression profiles and dimethyl disulfide (DMDS)-responsive differentially expressed genes (DEGs) between the control and treatment for leaves and stems, respectively. A, Pairwise Pearson's correlation coefficients of 12 expression profiles tested in this study. B, The comparison of DEGs between the control and treatment for leaf and stem tissues. An upregulated gene indicates that the expression value of the treatment was higher than that of the control. $\mathbf{C}$, Venn diagram of the number of upregulated and downregulated DEGs in leaf and stem tissues. D and E, Expression values of the selected DEGs determined using quantitative real-time PCR analyses in leaves and stems, respectively. F and G, Number of significantly enriched Gene Ontology (GO) terms and Kyoto Encyclopedia of Genes and Genomes (KEGG) pathways for DEGs in leaves and stems, respectively. $\mathrm{H}$, Classification of KEGG pathway DEGs involved. DEGs could be classified into various KEGG metabolic and signaling pathways, including pathways related to organismal systems, metabolism, and environmental information processing. An asterisk indicates that the KEGG pathway is significantly enriched in both leaf and stem tissues. 
2013). Our previous study also showed that Burkholderia pyrrocinia JK-SH007 had a strong inhibitory effect against three poplar canker pathogens (Ren et al. 2011). In the present study, we aimed to determine whether the VOCs released by strain JK-SH007 have an inhibitory effect on poplar canker pathogens. We found that VOCs produced by strain JK-SH007 indeed had an inhibitory effect on $C$. chrysosperma, $P$. macrospora, and $F$. aesculi (Table 1 ). VOCs can deform the mycelia of pathogens or inhibit the germination of spores, which makes pathogens lose the ability to absorb nutrients, grow, and reproduce (Supplementary Fig. S2) (Ren et al. 2013). To determine which components of JK-SH007 contributed the main inhibitory effect, three pathogenic fungi were incubated with different VOC components. The results showed that different VOCs had varied inhibitory effects on the three poplar pathogens, proving that the observed resistance to pathogens did not result from one microbial VOC alone but from multiple VOCs acting together.

Accordingly, VOCs produced by microorganisms can also induce plant resistance. For instance, $\beta$-caryophyllene produced by the Talaromyces fungus can induce the resistance of Brassica campestris to Colletotrichum higginsianum (Yamagiwa et al. 2011). VOCs can also enhance the transcription of resistance-related genes and hence increase resistance to various pathogens in plants (Yamagiwa et al.
2011). When plants perceive certain VOCs, they may undergo changes in the activity of related enzymes and gene expression in vivo, accelerating the metabolism and accumulation of nutrients and thus promoting plant growth (Avis et al. 2008; Compant et al. 2010; Tikhonovich and Provorov 2011). Here, an increase in the activities of defense enzymes in poplar was induced, indirectly enhancing the disease resistance of poplar. As shown in Figure 1, there was a significant difference in defense enzyme activity, MDA content, and TP content between the treatment and control. Moreover, many biocontrol bacteria, such as Bacillus subtilis and Pseudomonas fluorescens, can increase the number of roots and leaves, the root length, and the stem length of Mentha piperita through VOC release (Banchio et al. 2009).

Component analysis of the VOCs produced by microorganisms is helpful for understanding the metabolic process of microorganisms and providing reliable information that improves the use of microorganisms in biological control (Tait et al. 2014). Currently, SPMEGC-MS is a common method to study living biological samples, including VOCs (Radványi et al. 2015; Tait et al. 2014). Here, 13 main components were identified from strain JK-SH007 VOCs, and DMDS accounted for the largest proportion of VOCs $(84.8 \%$; Table 2). A previous study showed that VOCs produced by microorganisms could induce plant disease resistance to foreign pathogens
A

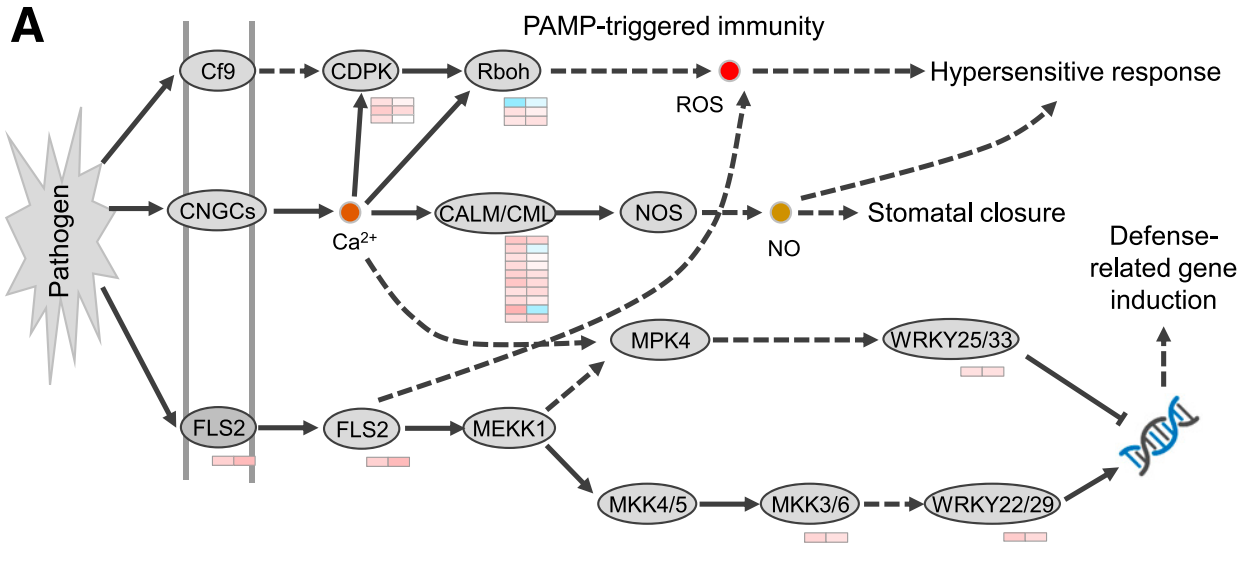

C

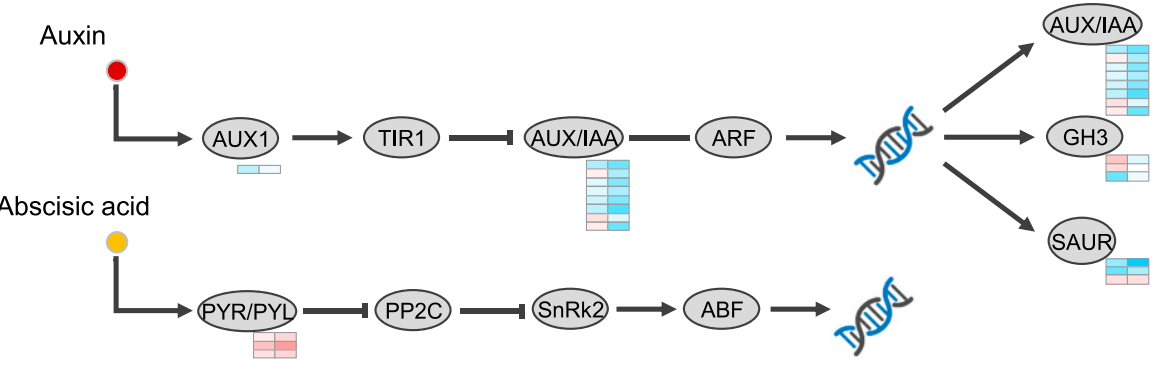

Ethylene

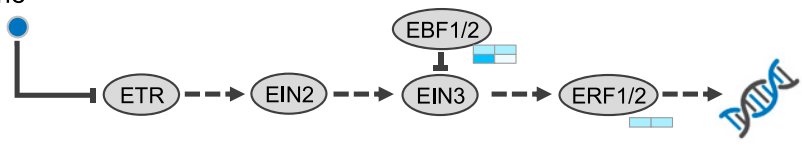

Salicylic acid

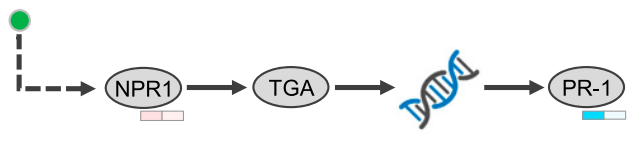

B

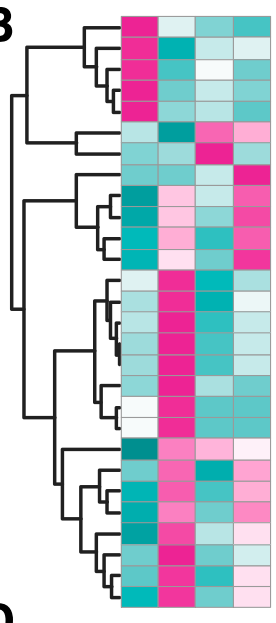

D

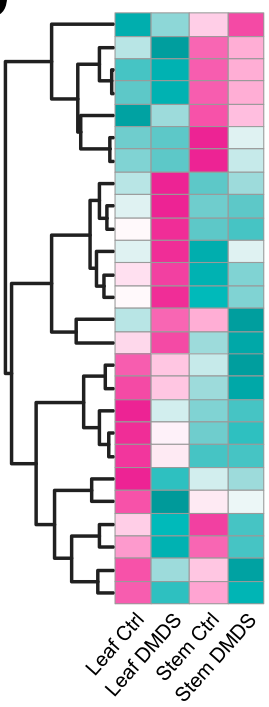

PtRBOHD1

PtAt4g272201

PtAt4g27220 2

PtAt4g27220 4

PtPR

PtCNGC2

PtARGH34
PtCBP

PtCBP
PtCPK1

PtCPK1
PtCML31

PtRBOHD

PtRBOHD
PtSP8

PtSP8
PtFLS2

PtFLS2

PtRBOHA

PtCBP
PtWRKY22

PtCML41

PtCML41.1

PtCML24.1

PtCDPK

PtCML8

PtCML24

PtCML

PtCBEF
PtCDPK

PtMMK4

PtSTK

PtNPR3

PtPR

PtLAX1

PtDFL1
PtGH3

PtGH3

PtIAA13

Ptaux/IAA

PtPYL4

PtGH3.1
PtAUX22D

PtPYL4

PtPYL4.1

PtARG7

PtIAA4

PtAUX22A

PtAUX22

PtauX/IAA1

PISAUR -1.5

PtAUX22B

PtBKI1

PtHPt

PtERF1B

PtERF1B 0

PtAt1g56140 -0.5

PtEBF

PtARF

Ptgrr1

Leaf Stem

Fig. 5. Differentially expressed genes (DEGs) involved in plant-pathogen-related immunity and hormone signal transduction induced by dimethyl disulfide (DMDS). A, lllustration of the mapped DEGs in the plant-pathogen-related immunity pathway modified from the Kyoto Encyclopedia of Genes and Genomes (KEGG) database (map04626). The heatmaps shown beside genes or gene clusters denote the $\log _{2}$ (fold change) of DEGs between the control and treatment for leaves and stems, respectively. B, Expression patterns of DEGs involved in plant-pathogen interactions shown as a heatmap. C, Illustration of the mapped DEGs in the hormone signal transduction pathway modified from the KEGG database (map04075). The heatmaps denote the same as A. D, Expression patterns of DEGs involved in plant hormone signal transduction shown as a heatmap. PAMP, pathogenassociated molecular pattern; CDPK, calcium-dependent protein kinase; RboH, respiratory burst oxidase; ROS, reactive oxygen species; CNGC, cyclic nucleotide-gated ion channel; CALM/CAL, calmodulin; NOS, nitric oxide synthase; NO, nitric oxide; MPK, mitogen-activated protein kinase; WRKY, WRKY transcription factor; FLS, flavonol synthase; MEKK, mitogen-activated protein kinase kinase kinase; MKK, mitogen-activated protein kinase kinase; SAUR, small auxin upregulated RNA. 
(Ryu et al. 2003). In this study, the volume gradient of the four main VOCs applied to poplar seedlings at different time intervals showed that DMDS had the greatest influence on defense enzyme activity, MDA content, and TP content (Fig. 3; Supplementary Figs. S7, S8, and S9). This is consistent with the observation via MS that among the VOCs produced by strain JK-SH007, DMDS had the highest content (Table 2). Therefore, it can be preliminarily concluded that the DMDS released from strain JK-SH007 is the main component of JK-SH007 affecting the induction of disease resistance in poplar.

Previous studies have also found that DMDS is a substance with inductive and antimicrobial effects released by microorganisms (Chuankun et al. 2004; Inglis et al. 2015; Kergunteuil et al. 2015; Ossowicki et al. 2017; Zou et al. 2007). Ossowicki et al. (2017) proved that DMDS has a significant inhibitory effect on $R$. solani and P. ultimum. Gu et al. (2007) evaluated the nematocidal activity of volatiles produced by 20 soil bacterial strains and found that DMDS and other compounds had effective nematocidal activity. In our study, the DEGs between the control and DMDS treatment groups were involved in significantly enriched GO terms and pathways related to disease resistance and growth (Supplementary Tables S2 and S3), and the relationship between DMDS and the induced disease resistance of poplar was further clarified. Despite the limitation of transcriptomics (Evans 2015), the results here provide us with a theoretical foundation for further research on the mechanism of disease resistance induced by the VOCs of strain JK-SH007. Furthermore, the qRT-PCR results further provided evidence for the reliability of the transcriptome data (Fig. 4D and E; Supplementary Fig. S10).

Accordingly, signaling pathways may be altered in variable physiological and biochemical processes, especially under environmental stress (Li et al. 2019b). The perception of VOCs by plants can trigger the differential expression of genes involved in plant-pathogenrelated immunity and hormone signal transduction and further activate downstream regulatory pathways for further adaptations (Tuteja and Sopory 2008). In our study, 65 DEGs, such as CAML and NPR1, were involved in plant-pathogen interactions and hormone signal transduction (Fig. 5). The expression of genes involved in metabolic processes, especially energy metabolism, was observed to change after DMDS inoculation. A total of 33 genes associated with starch and sucrose metabolism were identified, and more than half of these genes were upregulated (Supplementary Tables S2 and S3). A previous study showed that VOCs produced by Agrobacterium species, Pseudomonas syringae, and Bacillus subtilis could also increase the activity of starch synthase, the starch branching enzyme, and sucrose synthase and promote the accumulation of starch in plants (Ezquer et al. 2010). Moreover, there were many DEGs associated with other metabolism and biosynthesis terms (Supplementary Tables $\mathrm{S} 2$ and $\mathrm{S} 3$ ). In addition, there were many differentially expressed TFs involved in the DMDS response, such as WRKY, ERF, bHLH, and NAC (Fig. 6). Studies have indicated that members of these families can significantly affect the stress resistance of plants (Amorim et al. 2017; Nakashima et al. 2012), but further research is still required to verify their function extensively.

In summary, this study provides a systematic analysis of how gene expression differs in leaves and stems under VOC induction. A hypothetical schematic of VOC-induced signaling in poplar is summarized in Figure 7. In this schematic, VOCs are perceived, and the signal is mainly transduced further by plant-pathogen, hormone signal transduction, and energy metabolism genes, resulting in the activation of downstream TFs. The activation of VOC-induced genes through the involvement of TFs triggers a series of physiological and cell responses, such as defense enzyme activity promotion, MDA and TP accumulation, enhanced disease resistance, and growth promotion. Genes involved in plant pathogens, hormone signal transduction, and energy metabolism are logical targets for further studies and for the future development of improved disease tolerance in poplar cultivars. Our results provide an important reference for revealing the induction mechanism of poplar canker resistance. Because strain JK-SH007 was isolated from the poplar branch and could be stably colonized in poplar, the colonization of strain JK-SH007 could effectively reduce the occurrence of poplar canker disease. These results provide an important reference and theoretical basis for the prevention and control of poplar canker.
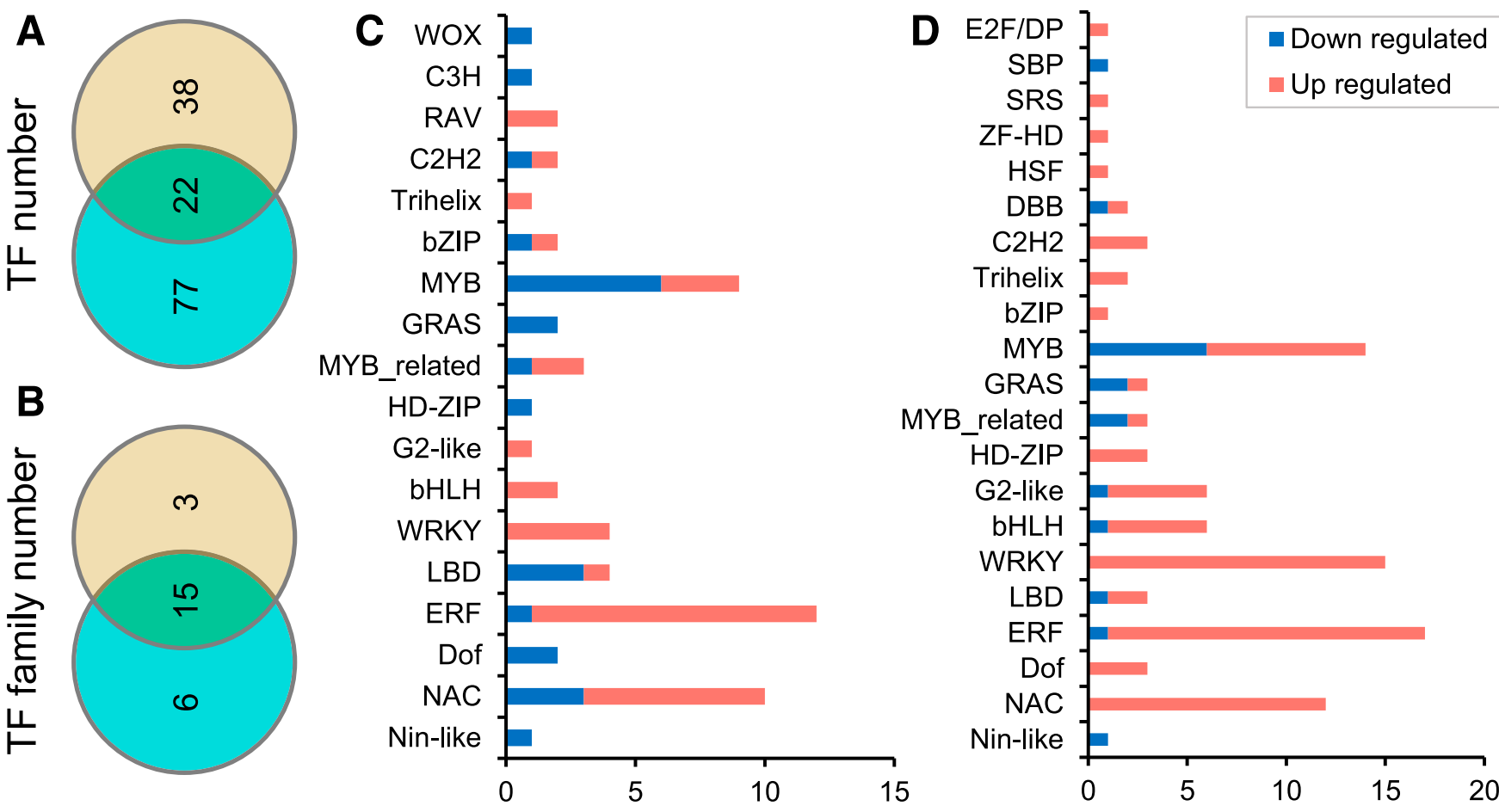

Fig. 6. Differentially expressed transcription factors (TFs) induced by dimethyl disulfide (DMDS) in leaves and stems. A and B, Venn diagrams of the gene and family numbers of differentially expressed TFs in leaf and stem tissues, respectively. Aquamarine blue and yellow represent the leaves and stems, respectively. $\mathbf{C}$ and $\mathbf{D}$, The number of upregulated and downregulated TFs in leaf and stem tissues, respectively, classified according to their responding families. 


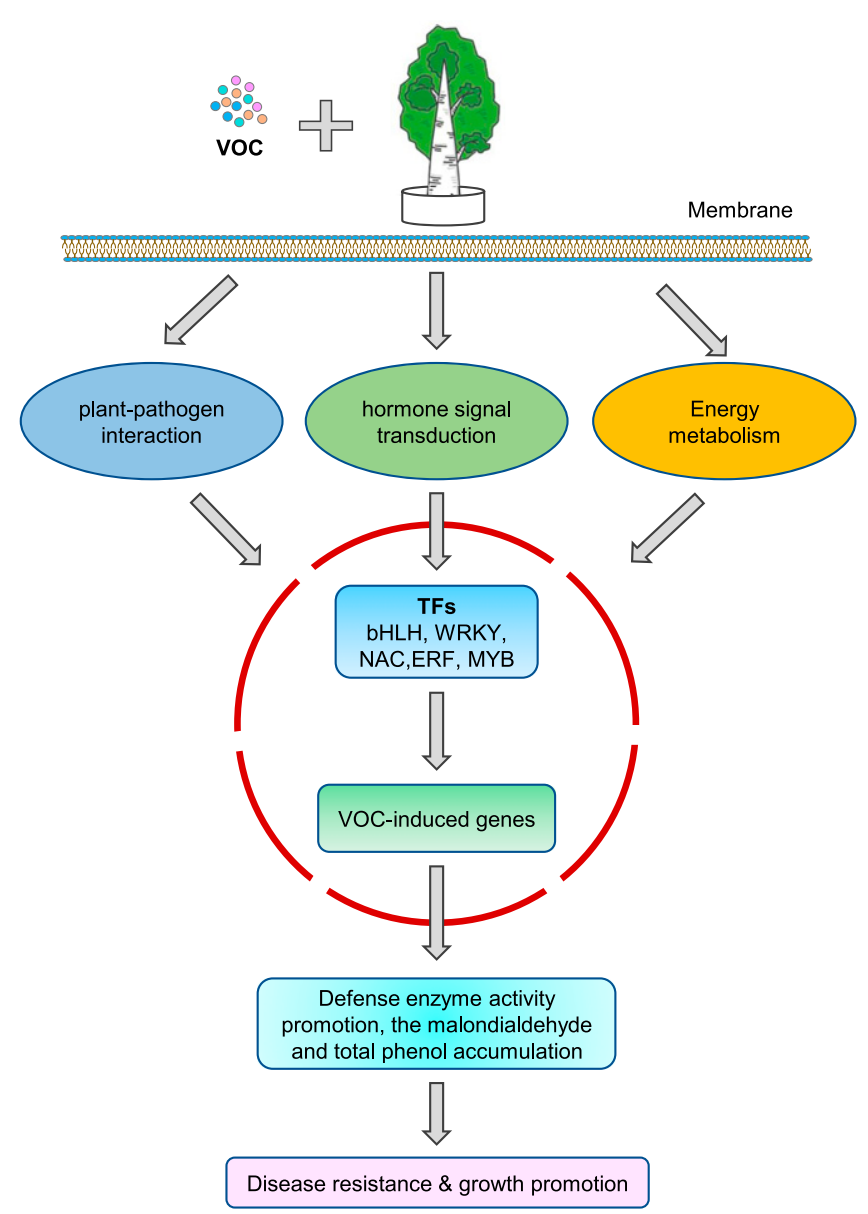

Fig. 7. Hypothetical schematic of the signaling and genes involved in the volatile organic compound (VOC)-induced promotion of growth and disease resistance in poplar. bHLH, basic helix-loop-helix protein; WRKY, WRKY transcription factor; NAC, NAC domain transcription factor; ERF, ethylene response factor; MYB, MYB transcription factor.

\section{Literature Cited}

Amorim, L. L. B., da Fonseca Dos Santos, R., Neto, J. P. B., Guida-Santos, M., Crovella, S., and Benko-Iseppon, A. M. 2017. Transcription factors involved in plant resistance to pathogens. Curr. Protein Pept. Sci. 18:335-351.

Asari, S., Matzen, S., Petersen, M. A., Bejai, S., and Meijer, J. 2016. Multiple effects of Bacillus amyloliquefaciens volatile compounds: Plant growth promotion and growth inhibition of phytopathogens. FEMS Microbiol. Ecol. 92:fiw070.

Avis, T. J., Gravel, V., Antoun, H., and Tweddell, R. J. 2008. Multifaceted beneficial effects of rhizosphere microorganisms on plant health and productivity. Soil Biol. Biochem. 40:1733-1740.

Banchio, E., Xie, X., Zhang, H., and Pare, P. W. 2009. Soil bacteria elevate essential oil accumulation and emissions in sweet basil. J. Agric. Food Chem. 57:653-657.

Benjamini, Y., and Hochberg, Y. 1995. Controlling the false discovery rate: A practical and powerful approach to multiple testing. J. R. Stat. Soc. B 57: 289-300.

Bhattacharyya, D., Yu, S. M., and Yong, H. L. 2015. Volatile compounds from Alcaligenes faecalis JBCS1294 confer salt tolerance in Arabidopsis thaliana through the auxin and gibberellin pathways and differential modulation of gene expression in root and shoot tissues. Plant Growth Regul. 75:297-306.

Bradford, M. M. 1976. A rapid and sensitive method for the quantitation of microgram quantities of protein utilizing the principle of protein-dye binding. Anal. Biochem. 72:248-254

Chen, Y., Li, F., Tian, L., Huang, M., Deng, R., Li, X., Chen, W., Wu, P., Li, M., Jiang, H., and Wu, G. 2017. The phenylalanine ammonia lyase gene LjPAL1 is involved in plant defense responses to pathogens and plays diverse roles in Lotus japonicus-rhizobium symbioses. Mol. Plant-Microbe Interact. 30: 739-753.

Cheniany, M., and Ganjeali, A. 2016. Developmental role of phenylalanineammonia-lyase (PAL) and cinnamate 4-hydroxylase $(\mathrm{C} 4 \mathrm{H})$ genes during adventitious rooting of Juglans regia L. microshoots. Acta Biol. Hung. 67: 379-392.
Chuankun, X., Minghe, M., Leming, Z., and Keqin, Z. 2004. Soil volatile fungistasis and volatile fungistatic compounds. Soil Biol. Biochem. 36: 1997-2004.

Compant, S., Clement, C., and Sessitsch, A. 2010. Plant growth-promoting bacteria in the rhizo- and endosphere of plants: Their role, colonization, mechanisms involved and prospects for utilization. Soil Biol. Biochem. 42: 669-678.

Concellón, A. A., Añón, M. A. C., and Chaves, A. R. 2004. Characterization and changes in polyphenol oxidase from eggplant fruit (Solanum melongena L.) during storage at low temperature. Food Chem. 88:17-24.

Ćurković Perica, M. 2008. Auxin-treatment induces recovery of phytoplasmainfected periwinkle. J. Appl. Microbiol. 105:1826-1834.

Cutler, S. R., Rodriguez, P. L., Finkelstein, R. R., and Abrams, S. R. 2010 Abscisic acid: Emergence of a core signaling network. Annu. Rev. Plant Biol. 61:651-679.

D’Alessandro, M., Erb, M., Ton, J., Brandenburg, A., Karlen, D., Zopfi, J., and Turlings, T. C. J. 2014. Volatiles produced by soil-borne endophytic bacteria increase plant pathogen resistance and affect tritrophic interactions. Plant Cell Environ. 37:813-826.

Dalio, R. J. D., Magalhaes, D. M., Rodrigues, C. M., Arena, G. D., Oliveira, T. S., Souza-Neto, R. R., Picchi, S. C., Martins, P. M. M., Santos, P. J. C., Maximo, H. J., Pacheco, I. S., De Souza, A. A., and Machado, M. A. 2017. PAMPs, PRRs, effectors and R-genes associated with citrus-pathogen interactions. Ann. Bot. 119:749-774.

Dandurishvili, N., Toklikishvili, N., Ovadis, M., Eliashvili, P., Giorgobiani, N., Keshelava, R., Tediashvili, M., Vainstein, A., Khmel, I., Szegedi, E., and Chernin, L. 2011. Broad-range antagonistic rhizobacteria Pseudomonas fluorescens and Serratia plymuthica suppress Agrobacterium crown gall tumours on tomato plants. J. Appl. Microbiol. 110:341-352.

Deng, S., Ma, J., Zhang, L., Chen, F., Sang, Z., Jia, Z., and Ma, L. 2019. De novo transcriptome sequencing and gene expression profiling of Magnolia wufengensis in response to cold stress. BMC Plant Biol. 19:321.

Dodds, P. N., and Rathjen, J. P. 2010. Plant immunity: Towards an integrated view of plant-pathogen interactions. Nat. Rev. Genet. 11:539-548.

Effmert, U., Kalderas, J., Warnke, R., and Piechulla, B. 2012. Volatile mediated interactions between bacteria and fungi in the soil. J. Chem. Ecol. 38:665-703.

Evans, T. G. 2015. Considerations for the use of transcriptomics in identifying the 'genes that matter' for environmental adaptation. J. Exp. Biol. 218:1925-1935.

Ezquer, I., Li, J., Ovecka, M., Baroja-Fernandez, E., Munoz, F. J., Montero, M., Diaz de Cerio, J., Hidalgo, M., Sesma, M. T., Bahaji, A., Etxeberria, E., and Pozueta-Romero, J. 2010. Microbial volatile emissions promote accumulation of exceptionally high levels of starch in leaves in mono- and dicotyledonous plants. Plant Cell Physiol. 51:1674-1693.

Fan, G., Dong, Y., Deng, M., Zhao, Z., Niu, S., and Xu, E. 2014. Plant-pathogen interaction, circadian rhythm, and hormone-related gene expression provide indicators of phytoplasma infection in Paulownia fortunei. Int. J. Mol. Sci. 15:23141-23162.

Fiddaman, P. J., and Rossall, S. 1993. The production of antifungal volatiles by Bacillus subtilis. J. Appl. Bacteriol. 74:119-126.

Gao, Z., Zhang, B., Liu, H., Han, J., and Zhang, Y. 2017. Identification of endophytic Bacillus velezensis ZSY-1 strain and antifungal activity of its volatile compounds against Alternaria solani and Botrytis cinerea. Biol. Control 105:27-39.

Garbeva, P., Hordijk, C., Gerards, S., and de Boer, W. 2014. Volatiles produced by the mycophagous soil bacterium Collimonas. FEMS Microbiol. Ecol. 87: 639-649.

Gene Ontology Consortium. 2015. Gene Ontology Consortium: Going forward. Nucleic Acids Res. 43:D1049-D1056.

Gu, Y., Mo, M., Zhou, J., Zou, C., and Zhang, K. 2007. Evaluation and identification of potential organic nematicidal volatiles from soil bacteria. Soil Biol. Biochem. 39:2567-2575.

Huang, K., Zhong, Y., Li, Y., Zheng, D., and Cheng, Z. M. 2016. Genome-wide identification and expression analysis of the apple ASR gene family in response to Alternaria alternata f. sp. mali. Genome 59:866-878.

Inglis, T. J., Hahne, D. R., Merritt, A. J., and Clarke, M. W. 2015. Volatile-sulfurcompound profile distinguishes Burkholderia pseudomallei from Burkholderia thailandensis. J. Clin. Microbiol. 53:1009-1011.

Jain, S., and Choudhary, D. K. 2014. Induced defense-related proteins in soybean (Glycine $\max$ L. Merrill) plants by Carnobacterium sp. SJ-5 upon challenge inoculation of Fusarium oxysporum. Planta 239:1027-1040.

Jiang, Y., Xia, B., Liang, L., Li, X., Xu, S., Peng, F., and Wang, R. 2013 Molecular and analysis of a phenylalanine ammonia-lyase gene (LrPAL2) from Lycoris radiata. Mol. Biol. Rep. 40:2293-2300.

Kanehisa, M., Sato, Y., Kawashima, M., Furumichi, M., and Tanabe, M. 2016 KEGG as a reference resource for gene and protein annotation. Nucleic Acids Res. 44:D457-D462.

Kergunteuil, A., Dugravot, S., Danner, H., van Dam, N. M., and Cortesero, A. M 2015. Characterizing volatiles and attractiveness of five brassicaceous plants with potential for a 'push-pull' strategy toward the cabbage root fly, Delia radicum. J. Chem. Ecol. 41:330-339.

Kim, D., Pertea, G., Trapnell, C., Pimentel, H., Kelley, R., and Salzberg, S. L. 2013. TopHat2: Accurate alignment of transcriptomes in the presence of insertions, deletions and gene fusions. Genome Biol. 14:R36. 
Konappa, N. M., Maria, M., Uzma, F., Krishnamurthy, S., Nayaka, S. C., and Chowdappa, S. 2016. Lactic acid bacteria mediated induction of defense enzymes to enhance the resistance in tomato against Ralstonia solanacearum causing bacterial wilt. Sci. Hortic. (Amsterdam) 207:183-192.

Lanna-Filho, R., De Souza, R. M., Magalhaes, M. M., Villela, L., Zanotto, E., Ribeirojunior, P. M., and De Resende, M. L. V. 2013. Induced defense responses in tomato against bacterial spot by proteins synthesized by endophytic bacteria. Trop. Plant Pathol. 38:295-302.

Li, C. X., Fu, X. P., Zhou, X. G., Liu, S. W., Xia, Y., Li, N. H., Zhang, X. X., and $\mathrm{Wu}$, F. Z. 2019a. Treatment with wheat root exudates and soil microorganisms from wheat/watermelon companion cropping can induce watermelon disease resistance against Fusarium oxysporum f. sp. niveum. Plant Dis. 103: 1693-1702.

Li, Y., Wang, X., Ban, Q., Zhu, X., Jiang, C., Wei, C., and Bennetzen, J. L. 2019b. Comparative transcriptomic analysis reveals gene expression associated with cold adaptation in the tea plant Camellia sinensis. BMC Genomics 20:624.

Liu, P., Cheng, Y., Yang, M., Liu, Y., Chen, K., Long, C. A., and Deng, X. 2014. Mechanisms of action for 2-phenylethanol isolated from Kloeckera apiculata in control of Penicillium molds of citrus fruits. BMC Microbiol. 14:242.

Lou, H., Wang, X., Chen, J., Wang, B., and Wang, W. 2018. Transcriptomic response of Ralstonia solanacearum to antimicrobial Pseudomonas fluorescens SN15-2 metabolites. Can. J. Microbiol. 64:816-825.

Lu, X. H., Sun, D. Q., Mo, Y. W., Xi, J. G., and Sun, G. M. 2010. Effects of postharvest salicylic acid treatment on fruit quality and anti-oxidant metabolism in pineapple during cold storage. J. Hortic. Sci. Biotechnol. 85:454-458.

Meshi, T., and Iwabuchi, M. 1995. Plant transcription factors. Plant Cell Physiol. 36:1405-1420.

Montero-Palmero, M. B., Martin-Barranco, A., Escobar, C., and Hernandez, L. E. 2014. Early transcriptional responses to mercury: A role for ethylene in mercury-induced stress. New Phytol. 201:116-130.

Nakashima, K., Takasaki, H., Mizoi, J., Shinozaki, K., and Yamaguchi-Shinozaki, K. 2012. NAC transcription factors in plant abiotic stress responses. Biochim. Biophys. Acta 1819:97-103.

Ossowicki, A., Jafra, S., and Garbeva, P. 2017. The antimicrobial volatile power of the rhizospheric isolate Pseudomonas donghuensis P482. PLoS One 12: e0174362.

Radványi, D., Gere, A., Jokai, Z., and Fodor, P. 2015. Rapid evaluation technique to differentiate mushroom disease-related moulds by detecting microbial volatile organic compounds using HS-SPME-GC-MS. Anal. Bioanal. Chem. 407:537-545.

Ren, J., Ye, J., Hui, L., Xu, X., and Wu, X. 2011. Isolation and characterization of a new Burkholderia pyrrocinia strain JK-SH007 as a potential biocontrol agent. World J. Microbiol. Biotechnol. 27:2203-2215.

Ren, J. H., Li, H., Wang, Y. F., Ye, J. R., Yan, A. Q., and Wu, X. Q. 2013. Biocontrol potential of an endophytic Bacillus pumilus JK-SX001 against poplar canker. Biol. Control 67:421-430.

Robinson, M. D., McCarthy, D. J., and Smyth, G. K. 2010. edgeR: A Bioconductor package for differential expression analysis of digital gene expression data. Bioinformatics 26:139-140.

Ryu, C. M., Farag, M. A., Hu, C. H., Reddy, M. S., Kloepper, J. W., and Pare, P. W. 2004. Bacterial volatiles induce systemic resistance in Arabidopsis. Plant Physiol. 134:1017-1026.

Ryu, C. M., Farag, M. A., Hu, C. H., Reddy, M. S., Wei, H. X., Pare, P. W., and Kloepper, J. W. 2003. Bacterial volatiles promote growth in Arabidopsis [published correction appears in Proc. Natl. Acad. Sci. USA 2003;100:8607]. Proc. Natl. Acad. Sci. USA 100:4927-4932.

Schwessinger, B., and Zipfel, C. 2008. News from the frontline: Recent insights into PAMP-triggered immunity in plants. Curr. Opin. Plant Biol. 11:389-395.

Sun, D., Lu, X., Hu, Y., Li, W., Hong, K., Mo, Y., Cahill, D. M., and Xie, J. 2013. Methyl jasmonate induced defense responses increase resistance to Fusarium oxysporum f. sp. cubense race 4 in banana. Sci. Hortic. (Amsterdam) 164:484-491.
Tahir, H. A., Gu, Q., Wu, H., Niu, Y., Huo, R., and Gao, X. 2017. Bacillus volatiles adversely affect the physiology and ultra-structure of Ralstonia solanacearum and induce systemic resistance in tobacco against bacterial wilt. Sci. Rep. 7:40481.

Tait, E., Perry, J. D., Stanforth, S. P., and Dean, J. R. 2014. Identification of volatile organic compounds produced by bacteria using HS-SPME-GC-MS. J. Chromatogr. Sci. 52:363-373.

Thiyagarajan, K., Vitali, F., Tolaini, V., Galeffi, P., Cantale, C., Vikram, P., Singh, S., De Rossi, P., Nobili, C., Procacci, S., Del Fiore, A., Antonini, A., Presenti, O., and Brunori, A. 2016. Genomic characterization of phenylalanine ammonia lyase gene in buckwheat. PLoS One 11:e0151187.

Tian, J. P., Ma, Z. Y., Zhao, K. G., Zhang, J., Xiang, L., and Chen, L. Q. 2019 Transcriptomic and proteomic approaches to explore the differences in monoterpene and benzenoid biosynthesis between scented and unscented genotypes of wintersweet. Physiol. Plant. 166:478-493.

Tikhonovich, I. A., and Provorov, N. A. 2011. Microbiology is the basis of sustainable agriculture: An opinion. Ann. Appl. Biol. 159:155-168.

Trapnell, C., Williams, B. A., Pertea, G., Mortazavi, A., Kwan, G., van Baren, M. J., Salzberg, S. L., Wold, B. J., and Pachter, L. 2010. Transcript assembly and quantification by RNA-Seq reveals unannotated transcripts and isoform switching during cell differentiation. Nat. Biotechnol. 28:511-515.

Tuteja, N., and Sopory, S. K. 2008. Chemical signaling under abiotic stress environment in plants. Plant Signal. Behav. 3:525-536.

Venisse, J. S., Gullner, G., and Brisset, M. N. 2001. Evidence for the involvement of an oxidative stress in the initiation of infection of pear by Erwinia amylovora. Plant Physiol. 125:2164-2172.

Vijayabharathi, R., Gopalakrishnan, S., Sathya, A., Srinivas, V., and Sharma, M. 2018. Deciphering the tri-dimensional effect of endophytic Streptomyces sp. on chickpea for plant growth promotion, helper effect with Mesorhizobium ciceri and host-plant resistance induction against Botrytis cinerea. Microb. Pathog. 122:98-107.

Wang, C., Wang, Z., Qiao, X., Li, Z., Li, F., Chen, M., Wang, Y., Huang, Y., and Cui, H. 2013. Antifungal activity of volatile organic compounds from Streptomyces alboflavus TD-1. FEMS Microbiol. Lett. 341:45-51.

Wang, Y., and Wu, X. 2008. Study on several kinds of poplar canker disease and the pathogenicity of the pathogens in north of Jiangsu. J. Nanjing For. Univ. (Nat. Sci. Ed.) 32:47-50.

Yamagiwa, Y., Inagaki, Y., Ichinose, Y., Toyoda, K., Hyakumachi, M., and Shiraishi, T. 2011. Talaromyces wortmannii FS2 emits $\beta$-caryphyllene, which promotes plant growth and induces resistance. J. Gene. Plant Pathol. 77:336-341.

Yu, J., Tang, X. X., Zhang, P. Y., Tian, J. Y., and Cai, H. J. 2004. Effects of $\mathrm{CO}_{2}$ enrichment on photosynthesis, lipid peroxidation and activities of antioxidative enzymes of Platymonas subcordiformis subjected to UV-B radiation stress. Acta Bot. Sin. 46:682-690.

Yue, Y., Liu, J., Shi, T., Chen, M., Li, Y., Du, J., Jiang, H., Yang, X., Hu, H., and Wang, L. 2019. Integrating transcriptomic and GC-MS metabolomic analysis to characterize color and aroma formation during tepal development in Lycoris longituba. Plants (Basel) 8:E53.

Zhang, Q., Yang, L., Zhang, J., Wu, M., Chen, W., Jiang, D., and Li, G. 2015 Production of anti-fungal volatiles by non-pathogenic Fusarium oxysporum and its efficacy in suppression of Verticillium wilt of cotton. Plant Soil 392:101-114.

Zhang, X., Li, B., Wang, Y., Guo, Q., Lu, X., Li, S., and Ma, P. 2013. Lipopeptides, a novel protein, and volatile compounds contribute to the antifungal activity of the biocontrol agent Bacillus atrophaeus CAB-1. Appl. Microbiol. Biotechnol. 97:9525-9534.

Zhao, L., Yang, X., Xiangying, L. I., Wei, M., and Liu, F. 2011. Antifungal, insecticidal and herbicidal properties of volatile components from Paenibacillus polymyxa strain BMP-11. Agric. Sci. China 10:728-736.

Zheng, M., Shi, J., Shi, J., Wang, Q., and Li, Y. 2013. Antimicrobial effects of volatiles produced by two antagonistic Bacillus strains on the anthracnose pathogen in postharvest mangos. Biol. Control 65:200-206.

Zou, C., Mo, M., Gu, Y., Zhou, J., and Zhang, K. 2007. Possible contributions of volatile-producing bacteria to soil fungistasis. Soil Biol. Biochem. 39:2371-2379. 